\title{
LAW AND THE SCIENCE OF NETWORKS: AN OVERVIEW AND AN APPLICATION TO THE "PATENT EXPLOSION"
}

\author{
Katherine J. Strandburg*
}

\begin{abstract}
The network may be the metaphor of the present era. A network, consisting of "nodes" and "links," may be a group of individuals linked by friendship; a group of computers linked by network cables; a system of roads or airline flights -- or another of a virtually limitless variety of systems of connected "things." The past few years have seen an explosion of interest in "network science," which seeks to move beyond metaphor to analysis in fields from physics to sociology. Network science highlights the role of relationship patterns in determining collective behavior. It underscores and begins to address the difficulty of predicting collective behavior from individual interactions. This Article seeks first to describe how network science can provide new conceptual and empirical approaches to legal questions because of its focus on analyzing the effects of patterns of relationships on collective behavior.

The Article then illustrates the network approach by describing a study of the network created by patents and the citations between them. Burgeoning patenting has raised concerns about patent quality, reflected in proposed legislation and in renewed Supreme Court attention to patent law. The network approach allows us to get behind the increasing numbers and investigate the patterns of relationships between patented technologies. We can then distinguish between faster technological progress, increasing breadth of patented technologies, and a lower patentability standard as possible explanations for increased patenting. We find that, since the late 1980s, the disparity in likelihood of citation between the most "citable" and least "citable" patents has grown, suggesting that the least citable patents may represent increasingly trivial inventions. One possible explanation of this increasing stratification is increasing reliance by the Federal Circuit Court of Appeals on the widely criticized "motivation or suggestion to combine" test for nonobviousness, which is at issue in the case of KSR v. Teleflex, currently pending at the Supreme Court. We also discuss how network science may be employed to address other issues of patent law.
\end{abstract}

\footnotetext{
* Associate Professor, DePaul University College of Law. This work was done in collaboration with Gabor Csardi, Peter Erdi, and Laszlo Zalanyi, Department of Biophysics, KFKI Research Institute for Particle and Nuclear Physics of the Hungarian Academy of Sciences, Budapest, Hungary, and Center for Complex Systems Studies, Kalamazoo College; and Jan Tobochnik, Department of Physics and Center for Complex Systems Studies, Kalamazoo College. We would like to thank Brett Frischmann, Stacey Dogan, Rochelle Dreyfuss, David Adelman, Jay Kesan, Michael Meurer, Joshua Sarnoff, participants at the Symposium on Complexity and Advanced Analytics Applied to Business, Government and Public Policy, University of Michigan-Dearborn, October 2004; the 2005 March Meeting of the American Physical Society; the Intellectual Property Scholars Conference at Cardozo Law School, August 2005; the Midwest Law and Economics Association meeting, October 2005; the Colloquium on Technology, Innovation, and Intellectual Property Policy, University of Arizona Law School, November 2005; a faculty workshop at the University of Illinois College of Law; and NetSci International Conference on Network Science, Bloomington, IN, May 2006 for helpful comments on this project. We are also grateful to Katherine Strandburg's research assistants, Douglas Burda and Elizabeth Levine, for substantive comments and assistance with preparing the manuscript.
} 


\title{
LAW AND THE SCIENCE OF NETWORKS: AN OVERVIEW AND AN APPLICATION TO THE "PATENT EXPLOSION"
}

\begin{abstract}
The network may be the metaphor of the present era. A network, consisting of "nodes" and "links," may be a group of individuals linked by friendship; a group of computers linked by network cables; a system of roads or airline flights -- or another of a virtually limitless variety of systems of connected "things." The past few years have seen an explosion of interest in "network science," which seeks to move beyond metaphor to analysis in fields from physics to sociology. Network science highlights the role of relationship patterns in determining collective behavior. It underscores and begins to address the difficulty of predicting collective behavior from individual interactions. This Article seeks first to describe how network science can provide new conceptual and empirical approaches to legal questions because of its focus on analyzing the effects of patterns of relationships on collective behavior.

The Article then illustrates the network approach by describing a study of the network created by patents and the citations between them. Burgeoning patenting has raised concerns about patent quality, reflected in proposed legislation and in renewed Supreme Court attention to patent law. The network approach allows us to get behind the increasing numbers and investigate the patterns of relationships between patented technologies. We can then distinguish between faster technological progress, increasing breadth of patented technologies, and a lower patentability standard as possible explanations for increased patenting. We find that, since the late 1980s, the disparity in likelihood of citation between the most "citable" and least "citable" patents has grown, suggesting that the least citable patents may represent increasingly trivial inventions. One possible explanation of this increasing stratification is increasing reliance by the Federal Circuit Court of Appeals on the widely criticized "motivation or suggestion to combine" test for nonobviousness, which is at issue in the case of KSR v. Teleflex, currently pending at the Supreme Court. We also discuss how network science may be employed to address other issues of patent law.
\end{abstract}




\section{LAW AND THE SCIENCE OF NETWORKS: AN OVERVIEW AND AN APPLICATION TO THE "PATENT EXPLOSION"}

I. INTRODUCTION II. NETWORK SCIENCE: WHAT IT IS AND WHY LEGAL SCHOLARS
SHOULD CARE

A. What Network Science Is

1. How to Describe a Network: Common Structural Signatures of Diverse Networks

a. Not Your Average Node: "Scale Free" Degree Distributions

b. Six Degrees of Separation: The "Small World" Property

c. Building Bridges: The "Betweenness" Metric

2. How Does Your Network Grow? "Preferential Attachment" and Other Factors in Network Evolution

3. Network Structure and Collective Behavior

B. Why Legal Scholars Should Care About Network Science

1. The Implications of Heterogeneity

2. The Importance of Local Relational Structure

3. The Complicated Influence of Local Relationship Patterns on Collective Behavior

III. NETWORK CLUES TO A DECREASING PATENTABILITY STANDARD

A. Background

1. The Patent System and Its Discontents

2. Patent Issuance and Prior Art Citations

3. Relationship of this Study to Previous Uses of Patent Citation Data

B The Evolving Patent Citation Network: Is Patenting Getting Out of Hand?

1. Concerning the Pace and Breadth of Innovative Progress

2. The Evolving Citability Distribution

3. Interpreting the Increasing Stratification of Patent Citation Patterns

IV. OF SLEEPER PATENTS AND INNOVATIVE PROGRESS: HOW INNOVATION BUILDS ON PRIOR TECHNOLOGY

V. FUTURE DIRECTIONS AND SOME PRELIMINARY RESULTS

A. Patent Classification and the Meaning of Analogous Arts

B. Patent Thickets and Potential Anti-Competitive Licensing Practices

VI. CONCLUSIONS 


\section{LAW AND THE SCIENCE OF NETWORKS: AN OVERVIEW AND AN APPLICATION TO THE "PATENT EXPLOSION"}

\section{INTRODUCTION}

The network seems to be the technological metaphor of the present era. Our fascination with networks is no doubt motivated in large part by the Internet, which not only ties us together technologically in ways that were not previously possible, but leads us to conceptualize the world in a more relational way. ${ }^{1}$ Once one picks up this conceptual lens, networks are everywhere. A network, consisting of "nodes" and "links," may be a group of individuals linked by friendship or commerce; a group of computers linked by network cables; a nervous system; a system of roads or airline flights; a collection of cracks in the earth; a group of patents and the citations between them -- or another of a virtually limitless variety of systems of connected "things."

Consistent with the increased salience of the network concept, the past few years have seen an explosion of interest in "network science," which attempts to move beyond the network metaphor to an analysis of commonalities between different networks. Natural and social scientists in fields from physics to sociology to biology have seized upon networks as important analytical and explanatory tools. ${ }^{2}$ Popular books and articles discuss the extent to which people, places, and things are "Linked"3 or separated by only

\footnotetext{
${ }^{1}$ See DARIN BARNEY, THE NETWORK SOCIETY (2004) for a critique of the ubiquitous application of the network metaphor to modern society.

${ }^{2}$ See, for overview discussions, e.g., Reka Albert and Albert-Laszlo Barabasi, Statistical Mechanics of Complex Networks, 74 ReV. Mod. Phys. 47 (2002); AlBert-LASZlo BARABASI, LinKED: The NeW SCIENCE OF Networks (2002); S. N. DOROGOVTSEV AND J. F. F. MENDES, EVOlution OF NeTWORKS From Biological Nets to the InTERnet AND WWW (2003); M. E. J. Newman, The Structure and Function of Complex Networks, 45 SIAM Rev. 167-256 (2003); ROMUALDO PASTOR-SATORRAS AND

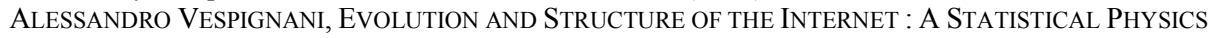
Approach (2004); Duncan J. Watts, Six Degrees: The Science of a Connected Age (2002); Peter J. CARRINGTON, JoHn SCOTT AND STANLEY WASSERMAN, MODElS AND METHOdS IN SOCIAL NeTWORK ANALYSIS (2005).

${ }^{3}$ BARABASI, supra note 2.
} 
"Six Degrees." Prominent universities have inaugurated inter-disciplinary centers and programs relating to the study of networks. ${ }^{5}$ Most recently, a few legal scholars have begun to apply some of the techniques and insights of network science to the empirical and theoretical study of law. ${ }^{6}$

This Article seeks to accomplish two things with respect to the application of network science to the study of law. First, it seeks to persuade readers that legal scholars should jump on the network bandwagon in greater numbers because of the important conceptual advances and analytical tools that network science provides. Specifically, network science highlights the potential importance of heterogeneity and local relationship patterns in determining collective behavior. It also underscores and begins to address the difficulty of predicting collective behavior from individual interactions or

\footnotetext{
${ }^{4}$ WATTS, supra note 2.

${ }^{5}$ See, e.g., The University of Illinois "Age of Networks" program, at http://www.cas.uiuc.edu/networks.html; Cornell University's Institute for the Social Sciences Theme Project 2005-08, "Getting Connected: Social Science in the Age of Networks," at http://www.socialsciences.cornell.edu/0508/networks_desc.html; and Northwestern University's Institute on Complex Systems, at http://www.northwestern.edu/nico.

${ }^{6}$ The application of network science to law is in its infancy. While many law review articles deal with the topic of network effects or discuss the Internet and other networked infrastructure, the paucity of articles applying network science or modeling from a statistical physics, computer science, or social network theory perspective is evident. For example, a LEXIS search for law review articles citing either of the authors of the most well-known popular works on network science (BARABASI, supra note 2 or WATTS, supra note 2), uncovers only about ten articles making more than a passing reference to network science. Yet even this small group demonstrates the breadth of potential applications of network science to legal scholarship. See, e.g., Ian Ayres and Katharine K. Baker, A Separate Crime of Reckless Sex, 72 U. CHI. L. REv. 599 (2005); Claire Moore Dickerson, Corporations As Cities: Targeting the Nodes in Overlapping Networks, 29 IOwA J. CORP. L. 533 (2004); Andrea M. Matwyshyn, Of Nodes and Power Laws: A Network Theory Approach to Internet Jurisdiction Through Data Privacy, 98 Nw. U.L. REV. 493 (2004); Lior Jacob Strahilevitz, A Social Networks Theory of Privacy, 72 U. CHI. L. REV. 919 (2005); Lawrence Mitchell, Structural Holes, CEOs and Informational Monopolies: The Missing Link in Corporate Governance, 70 Brooklyn L. ReV. 1313 (2005); Daniel F. Spulber and Christopher S. Yoo, On the Regulation of Networks as Complex Systems: A Graph Theory Approach, 99 Nw. U. L. REV. 493 (2005). We are also aware of related work by Thomas A.C. Smith, The Web of Law, San Diego Legal Studies Research Paper No. 06-11, available at: http://ssrn.com/abstract=642863 (Spring 2005); Seth J. Chandler, The Network Structure of Supreme Court Jurisprudence, University of Houston Law Center No. 2005-W-01, available at: http://ssrn.com/abstract=742065 (June 10, 2005); Tracey L. Meares and Kelsi Brown Corkran, When 2 or 3 Come Together, U of Chicago, Public Law Working Paper No. 107, available at: http://ssrn.com/abstract=835664 (October 2005); and Gavin Clarkson (abstract to be presented at Symposium on Law in the Age of Networks: Implications of Network Science for Legal Analysis, March 10, 2005, available at http://www.cas.uiuc.edu/networkslaw.html).
} 
transactions. As the science of networks continues to develop, it promises to provide new approaches to the analysis of empirical data and new tools for modeling the expected results of legal change. These analytical approaches and modeling tools complement the existing empirical methods and theoretical models of law and economics and other interdisciplinary approaches. Part II of this Article examines the general potential for network science to contribute to legal analysis.

In Parts III and IV, the Article illustrates the application of a network approach to empirical data by describing some results of a network science study of patent citations. The overall goal of the study is to gain a better understanding of the evolution and structure of technical relationships between patents in the United States patent system, and to investigate current patenting behavior so as to gain insight into innovation policy and law. The United States patent system has been the subject of increasing criticism in recent years. ${ }^{7}$ There is a perception that recently issued patents sweep more broadly than is justified by their inventors' contributions and that some are being issued for inventions that should be deemed obvious. Critics also contend that patents increasingly impose transaction costs in areas, such as scientific research, software, and business methods, in which patents may not be needed to promote technological advances. These criticisms

\footnotetext{
${ }^{7}$ See, e.g., Federal Trade Commission, To Promote Innovation: The Proper Balance of Competition and Patent Law and Policy, Report (October 2003) and references therein; Stephen A. Merrill,, Richard C. Levin, and Mark B. Myers, eds., A PATENT SYSTEM FOR THE $21{ }^{\text {ST }}$ CENTURY, NATIONAL RESEARCH COUNCIL OF THE NATIONAL ACADEMIES (2004) and references therein; Michael Heller and Rebecca S. Eisenberg, Can Patents Deter Innovation? The Anticommons in Biomedical Research, 280 SCIENCE 698701 (May 1998); ADAM B. JAFFE AND JOSH LERNER, INNOVATION AND ITS DISCONTENTS: HOW OUR BRoKen PATENT System is EndANGERING InNOVATION AND Progress AND What to Do About IT, Princeton University Press (2004) and references therein; Rochelle C. Dreyfuss, Pathological Patenting: The PTO as Cause or Cure, 104 MiCH. L. REV. (forthcoming 2006) (critiquing the Jaffe and Lerner book for its emphasis on patent invalidity and pointing out other potential sources of problems with the patent system).
} 
are reflected in recently proposed legislation ${ }^{8}$ and in renewed Supreme Court attention to patent law. ${ }^{9}$ Responses to the criticism highlight the contributions of intellectual property to the nation's economy and argue that increasing numbers of patents do not necessarily signify an erosion of patent quality. ${ }^{10}$

Part III of this Article employs a network science approach to interpreting the burgeoning patenting of the past few decades. ${ }^{11}$ In our study, the "nodes" of the network are United States patents and the "links" are citations of one patent by another. ${ }^{12}$ Patent citations indicate technological relationships between the patented technologies. For the most part, a citation from one patent to another indicates either that the later patent builds upon the technology of the earlier patent or that the claimed inventions are closely enough related that the earlier technology was material to determining whether the later patent should be issued. The citation network thus provides a "map" of the relationships between patented technologies which can be explored using network science techniques.

We have performed a detailed study of the evolution of the patent citation network since 1975. In looking at how the network structure has evolved, we distinguish

\footnotetext{
${ }^{8}$ See H.R. 2795, Patent Reform Act of 2005.

${ }^{9}$ See Merck KGaA v. Integra Lifesciences I, Ltd., 125 S. Ct. 2372 (2005); Unitherm Food Systems, Inc. v. Swift Eckrich, Inc., Supreme Court No. 04-597; Illinois Tool Works, Inc. v. Independent Ink, Inc., Supreme Court No. 04-1329; Laboratory Corp. of America Holdings v. Metabolite Laboratories, Inc., Supreme Court No. 04-607 (cert granted Oct. 31, 2005, but dismissed as improvidently granted with dissent on ); eBay, Inc. v. MercExchange, LLC, Supreme Court No. 05-130; KSR Int'l Co. v. Teleflex, Inc., No. 04-1350 (pending as of August 22, 2006) See also Marcia Coyle, Justices Ponder Heavy Patent Docket: David vs. Goliath Case One of Many Patent Disputes Before Supreme Court, THE NATIONAL LAW JouRnaL (December 12, 2005), available at http://www.law.com/jsp/article.jsp?id=1134122713321 (arguing that increased Supreme Court attention to patent law is due to "[a] constellation of factors, according to scholars and litigators, not the least of which is unhappiness with the U.S. Court of Appeals for the Federal Circuit").

${ }^{10}$ See, e.g., Dudas: Perception Gap Hindering Efforts to Improve Patent System, 71 BNA's PATENT, TRADEMARK AND COPYRIGHT J. 374 (Feb. 10, 2006).

${ }^{11}$ Our patent citation study is similar in flavor to recent studies of citations in scientific journal articles, see S. Redner, Citations Statistics from 110 Years of Physical Review, PHYSICS TODAY 58, 49 (2005), and of the "web of law" consisting of cases and other legal authorities and the citations linking them. See Smith, supra note 6 and Chandler, supra note 6.

${ }^{12}$ United States patents also cite scientific literature and foreign patents. Our data do not include these additional links.
} 
between three possible explanations of the recent increase in patenting -- faster technological progress; increasing breadth of patented technologies due either to expansion of patentable subject matter or to new fields of invention; and a lowering of the legal standard for patentability leading to the issuance of patents for more trivial innovative steps. These possibilities are not mutually exclusive, of course, nor are they the only factors that might affect citations patterns. The question we ask here is whether the observed evolution of the patent network can be explained solely in terms of an increasing pace and breadth of technological advance or whether some additional factor is needed to understand the observed network growth and structure.

Our analysis leads us to conclude that increasing pace and breadth of innovation alone are unlikely to explain the way in which the patent citation network has evolved in recent years. This is primarily because, as we explain in detail in Part III, the citation network has undergone a measurable increase in stratification since the late 1980s, following a modest decrease earlier in the decade. Here, by "increasing stratification" we mean that there is an increasing disparity in likelihood of citation between the most "citable" and least "citable" patents. Because econometric studies have indicated that patent citations are linked to the technological importance of the patented technology, ${ }^{13}$ a reasonable interpretation of this observation is that patents are being issued for increasingly trivial advances. ${ }^{14}$ The timing of the increasing stratification is roughly correlated with increasing reliance by the Federal Circuit Court of Appeals on the widely

\footnotetext{
${ }^{13}$ See, e.g., John R. Allison, Mark A. Lemley, Kimberly A. Moore and R. Derek Trunkey, Valuable Patents, 92 GEORGETOWN L.J. 435, 449 (2004) and citations therein.

${ }^{14}$ Other possible interpretations are discussed, infra.
} 
criticized "motivation or suggestion to combine" test for nonobviousness, ${ }^{15}$ and with other indications of an increasingly lax legal standard of patentability. ${ }^{16}$

In Part IV of this Article we describe how network science illuminates the question of how innovation proceeds by combining prior technologies. We briefly review some earlier studies of the innovative process using a network approach and then present results for the dependence of patent citability on the age of the patent. Patent citability dies out surprisingly slowly with age even for patents that have rarely or never been previously cited. This means that there are "sleeper" patents which are cited after long periods of neglect, perhaps signifying how innovation proceeds not only by building incrementally on previous advances but also by "doubling back" to make new use of previously neglected technology. These results cast doubt on the possibility that the value of an innovation can be identified confidently at the time of patenting. ${ }^{17}$

Part V of the Article briefly describes some other possibilities for applying network science to the patent citation network to explore questions of legal significance. We first describe how the network concept of path length may be useful in quantifying the "closeness" of patented technologies. Numerous patent law doctrines, including patent validity and patent infringement under the doctrine of equivalents, are based on the

\footnotetext{
${ }^{15}$ See Manual of Patent EXAmining Procedures, (hereinafter "MPEP") § 2143.01; See, e.g., In re Rouffet, 149 F.3d 1350, 1357 (Fed. Cir. 1998). The "suggestion test" has its roots much earlier in the jurisprudence of the Court of Customs and Patent Appeals. See CHISUM ON PATENTS § 5.04[1][e] for a discussion of the history of the test. However, it took on its modern form and became increasingly important at the Federal Circuit throughout the 1990s. The percentage of opinions involving nonobviousness citing the suggestion test rose from about $10-15 \%$ in the late 1980 s to about $40-50 \%$ in the late 1990s. (See Figure 11.)

${ }^{16}$ See, e.g., Glynn S. Lunney, Jr., Patent Law, the Federal Circuit, and the Supreme Court: A Quiet Revolution, 11 S. CT. ECON. REV. 1, 14-17 (2004); John H. Barton, Non-Obviousness 43 IDEA 475 (2003)

${ }^{17}$ See, e.g., Allison et al, supra note 13, arguing for metrics to identify valuable patents; David E. Adelman and Kathryn L. DeAngelis, Mapping the Scientific Commons: Biotechnology Patenting from 1990 to 2004 Arizona Legal Studies Discussion Paper No. 06-10, available at http://ssrn.com/abstract=881842. (critiquing the approach of Allison et al.).
} 
perspective of the "person having ordinary skill in the art" or "PHOSITA."18 In addition, the obviousness of a claimed invention is judged in light of prior inventions in "analogous arts."19 Assessing the "closeness" of different technologies is essential to interpreting the concept of an "art" in applying these doctrines and is also of practical importance to patent classification.

Next, we describe network metrics that may be of use in exploring the extent to which closely related patented technologies are complements or substitutes, which is relevant to the problem of "patent thickets" and to issues of anti-competitiveness in patent licensing. Finally, we discuss how a network perspective may help in understanding citation practice itself by comparing the patterns of citations made by patent applicants and examiners, respectively.

Part VI offers conclusions and returns to the broader point of this Article that network theory and modeling, as they are applied in social network analysis, computer science, statistical physics, and elsewhere, have great potential to complement other interdisciplinary approaches to the analysis of present and proposed legal doctrine.

\section{NETWORK SCIENCE: WHAT IT IS AND WHY LEGAL SCHOLARS SHOULD CARE}

\section{II.A. What Network Science Is}

Network science, whether it is rooted in the social sciences, computer science, or the natural sciences such as physics or biology, has three general, interrelated and ongoing goals: 1) to measure, describe, and categorize network structure and the patterns of relationships between network nodes; 2) to understand network evolution and growth

\footnotetext{
${ }^{18}$ See, e.g., Dan L. Burk and Mark A. Lemley, Is Patent Law Technology-Specific?, 17 Berkeley TeCH. L.J. 1155 (2002) for a discussion of the importance of the PHOSITA in patent law.

${ }^{19}$ See, e.g., In re Clay, 966 F.2d 656, 658 (Fed. Cir. 1992).
} 
and its relationship to network structure; and 3) to understand how the collective behavior of entities connected in a network depends on and derives from the network's structure. Many open questions exist at all three levels. The overall intuition behind the interdisciplinary conversations that characterize "network science" is that common structures, growth patterns, and collective behaviors will arise in networks composed of very different kinds of elements and linkages. If this is the case, common concepts and methods will be useful in understanding widely varying networks and in answering the very different substantive questions posed by physicists, biologists, computer scientists, sociologists and, most recently, by legal scholars.

\section{II.A.1 How to Describe a Network: Common Structural Signatures of Diverse Networks}

Network science seeks at the outset to measure and describe various relational structures found in the social or physical world. In a network in which the node is an individual, the links might be relationships of friendship, kinship, sexual involvement, business association and so forth. When the node is an airport, the links might be flight paths. When the node is a business entity, the links might be supply and distribution relationships. And when the node is a patent, scientific journal, or legal opinion, the links can be citations.

The descriptive task of network science necessitates thinking about what quantities characterize networks -- what metrics provide concise, yet illuminating, means of describing and comparing relational structures. It aims at more than simply providing a means to parameterize individual network structures. Part of the fascination of network science is that similar metrics -- degree distribution, "transitivity," network "path lengths," and others (some of which are discussed in this Article) -- may be used to 
describe networks of very different "nodes" and "links." 20 Strikingly similar results are obtained for some of these metrics when seemingly disparate networks are measured. The broader descriptive goal is to delineate the similarities and differences between networks with the hope of categorizing these structures in a logical way that can provide substantive insights into the underlying systems.

\section{II.A.1.a Not Your Average Node: "Scale Free" Degree Distributions}

For example, the "degree" of a node is the number of connections or "links" it has to other nodes. Node degree is an intuitive measure of "importance." A person in a social network who has many connections to others likely plays an important role in that network, for example. Of course, the meaning of such importance will be very different in a network of friends than it is in a network of legal citations but the network approach brings to light underlying similarities between very different networks. One way to characterize a network is to study the "node degree distribution." The node degree distribution charts the fraction of nodes in the given network that have a particular number of connections or "degree." (See Figure 1, which plots the node degree distribution for the patent citation network, for an example.)

If a network is produced by randomly connecting nodes to one another with a uniform probability of connection, the degree distribution will be symmetrically peaked around a "typical" number of edges determined by that probability of connection. (See Figure 2.) For large networks, the peak will be very narrow, so that most nodes will have the "typical" number of edges or close to it. In this sense, the nodes of a random network can be said to be relatively homogeneous. In the random network underlying Figure 2, for example, the most common number of connections for a node is twenty -- and this is

${ }^{20}$ See, e.g., references supra note 2. 
also the average and median number. Though there are plenty of nodes with ten to thirty connections, once one gets much outside the peak width, the numbers drop drastically.

There are virtually no nodes with 100 connections.

The symmetrical, peaked distribution of Figure 2 is similar to the "normal" distribution or "Bell curve" that characterizes the probability distribution of many things in our everyday experience ${ }^{21}$-- such as the height of human beings, for example. (See Figure 3 for an example of a normal distribution.) The fact that the height of human beings has this kind of "normal" probability distribution makes it possible to design furniture, showers, cars, and the like for the "average" person and to expect that nearly all people will be able to use them, perhaps with minor adjustments.

One of the first -- and still one of the most interesting -- results of network science was the discovery that many networks encountered in the real world are not homogeneous like the random networks with degree distributions as illustrated in Figure 2. Indeed, the degree distributions of many real world networks look nothing like normal distributions. Instead, many real world degree distributions are highly skewed, and very broad, with what are called "fat tails." (See Figure 1.) In these networks, rather than all nodes having roughly the same "typical" number of links, there are a large number of nodes with very few links, but there are also a small, but significant, number of nodes with very many links. These highly connected nodes may have hundreds or thousands of times as many connections as the "average" or "typical" node. Depending upon the network, the few highly connected nodes may play a much more important role than the

\footnotetext{
${ }^{21}$ The probability distribution for the node degree of a random graph is not precisely a normal or "Gaussian" distribution. Mathematically, it takes another typical form for probability distributions -- the Poisson distribution. See Newman, supra note 2 at 9 . For present purposes, the difference is unimportant. What is important is the peaked, symmetrical shape.
} 
large number of minimally connected nodes. In this kind of situation, it is not enough to make decisions based on the likely behavior of "typical" nodes. Because a significant fraction of nodes are so far from "typical," the effects of non-typical nodes must be taken into account in understanding and predicting the behavior of the network. For example, in a communications network, the system might continue to operate despite failures of many "typical" nodes, but may be completely defeated by the failure of one highly connected node. Any attempt to understand the collective behavior of such a network by focusing on the "typical" node is doomed to fail.

When the degree distribution is sufficiently broad, it will have a "power law" decaying tail. In some cases, network degree distributions may be so broad that they do not even have well-defined averages or "widths." Figure 4 illustrates a "power law" degree distribution, meaning that the fraction of nodes with a particular number of connections decays as $d^{-\gamma}$ once $d$ is large (where $d$ is the degree of a node). Figure 4 shows how, the smaller the decay power $\gamma$ becomes, the more difficult it becomes to identify a "typical" node. When $\gamma$ is 3 , the most likely number of connections is 0 , while the median number is about 15 and the average number is about 20 . When $\gamma$ is even smaller, the most likely number of connections is still 0 , but the median number is 40 and the average is essentially infinite because there are so many nodes with very large numbers of connections. The likelihood of having a particular number of connections for $\gamma=1.5$ is fairly flat and it would be a mistake to say that a node with 10,40 , or 100 connections is "typical."

Because there is no "typical" number of links for a node in a power law distribution, such networks are often termed "scale free," meaning roughly that there is 
no typical "scale" that can be used to describe the network. In such a "scale free" situation, knowing, for example, that the average number of links per node is 12 is not useful for predicting the collective behavior of the network because there are significant numbers of nodes with no links and significant numbers of nodes with hundreds or thousands of links. ${ }^{22}$ Decisions, plans, or predictions based on the "average" node degree can go badly awry. An example of this kind of situation is the attempt to estimate the spread of a virus, such as HIV. While the average number of sexual partners per person may be quite small, if, as appears to be the case, the distribution is sufficiently broad (effectively scale free), there are a small but significant number of individuals who have hundreds of sexual partners. ${ }^{23}$ Any predictions of how fast the virus will spread based on the "average" number of sexual partners will be completely wrong. ${ }^{24}$ Moreover, a program of random condom distribution or HIV testing may be much less effective than anticipated if it happens to "miss" the few most highly active individuals.

Highly skewed and broad degree distributions are common in networks of widely varying types, including the physical connections and hardware of the Internet; the hyperlinks of the World Wide Web; the networks of co-authorship of high energy physics papers and of co-appearances of movie actors; networks of sexual contacts; metabolic networks; phone call networks; networks of word uses; protein interaction networks; and many others. ${ }^{25}$ Other observed networks, such as the power grid, do not have a scale free or nearly scale free form, however. Thus, the degree distribution is a metric which can be

\footnotetext{
${ }^{22}$ More precisely, a "scale free" network is one in which the large degree tail of the node degree distribution decays as a power of the degree, $\mathrm{P}(\mathrm{k}) \sim \mathrm{k}^{-\mathrm{a}}$, rather than exponentially with the degree, as more well known probability distributions do. Technically, the term "scale free" should be reserved for networks in which the node degree distribution has a power law decay. In reality, it is sometimes difficult to tell a true "power law" decay from a very broad, skewed distribution with an exponentially decaying tail.

${ }^{23}$ Ayres and Baker, supra note 6 at 607-11.

${ }^{24} I d$.

${ }^{25}$ See Albert and Barabasi, supra note 2 and Newman, supra note 2.
} 
used to categorize networks and to differentiate between them with respect to how they may behave. In the legal context, knowing how networks -- such as drug distribution networks (legal and illegal), communications networks, infectious networks, terrorist networks, and the social networks of ordinary citizens -- tend to be organized may be very important in devising effective policy and law.

\section{II.A.1.b Six Degrees of Separation: The "Small World" Property}

Another commonly observed attribute of real world networks is the "small world" property, in which a relatively small number of "hops" between nodes is needed to connect any two nodes in the network. ${ }^{26}$ The small world property can be important in determining the rate at which something -- which might be a fad, a piece of information, or a deadly virus -- spreads across the network. The small world property is often related to the presence of highly connected "hubs" in the network, which connect otherwise widely separated nodes (as in the sexual contact example already mentioned). But this is not always the case. A random network with a degree distribution like that shown in Figure 2 can have the small world property, as can a regular network (think of a fishnet, for example), after a small amount of "re-wiring" to connect distant parts of the network. $^{27}$ "Re-wiring" occurs in a social network, for example, whenever one person moves to a distant location and maintains social contacts in both locations. The person who moves from Chicago to New York broadens not only her own choice of friends, but

\footnotetext{
${ }^{26} I d$.

${ }^{27}$ See Duncan J. Watts and Steven H. Strogatz, Collective Dynamics of Small World Networks, 393 NATURE 440 (1998) for discussions of the basic properties of small world networks. The term "small world" is used in two slightly different senses: to denote the property of short "distance" between nodes and to denote that property joined with the additional element of local clustering (more technically, high "transitivity"). We discuss transitivity below at note 109 and associated text, but by the "small world property" here we will mean short "distances" between nodes. By short, we mean, technically, that the longest distance between two nodes grows only logarithmically with the number of nodes. Intuitively, this means that it is impossible to make a spatial "map" of the network in which nodes that are connected to one another are near to one another. You will always end up with some connections between "far apart" nodes.
} 
also the choices of all her friends and relations who may meet New Yorkers through her.

The presence or absence of the small world property is thus an additional metric which may be used to categorize observed networks and to understand their behavior.

\section{II.A.1.c Building Bridges: The Betweenness Metric}

Node degree is only one possible way to measure the importance of a network node. Depending on the circumstances, the number of connections a node has may be less important than its specific place in the network structure. A node with few links may play a critical part in connecting different parts of a network. The friend who moved to New York may not have been the most popular person in the Chicago social network, but she may be the only connection to New York which the social group has. In that case, she will have a relatively low node degree, but a relatively high "betweenness centrality."28 For some purposes a network may be more dependent on high "betweenness" nodes than on those with high node degree.

The above examples give a brief glimpse of the ways networks can be characterized by their patterns of node relationships and of how the network structure can affect the collective behavior of the network. The next section discusses how the structure of a network is related to the way in which it evolves.

\section{II.A.2 How Does Your Network Grow? "Preferential Attachment" and Other Factors in Network Evolution}

Degree distributions, small world properties and other measures are useful in describing and categorizing real world networks. The aim of this descriptive task is not simply the "gee-whiz" satisfaction of seeing similar graphs show up for widely differing networks (though physicists, at least, do derive an inordinate amount of pleasure from

I ${ }^{28}$ See, e.g., CARRINGTON, SCOTT, AND WASSERMAN, supra note 3, for definitions of this and other network metrics.

Deleted: SCOTT 
such observations of "universality"). The underlying intuition driving the descriptive enterprise is that similar structures probably result from similar mechanisms of network growth and evolution, and that networks with similar structures will behave in similar ways. Making the connection between the mechanisms by which a network evolved and the network's eventual structure is the second task of network science.

For example, in many cases (though not always) a "scale free" degree distribution results from what is called the "preferential attachment" mechanism. "Preferential attachment" (also sometimes called the "rich get richer" effect) describes a process for creating a network in which "popular" nodes, which already have many links, are more likely than others to gain additional links as nodes are added to the network. Preferential attachment can lead to a highly heterogeneous, scale-free, degree distribution in which some nodes eventually acquire a very large number of links while others remain relatively unconnected.

Why does this happen? In some cases, the nodes of the network may have a highly skewed distribution of "quality" which becomes reflected in the network connectivity. In a social network sociable people attract friends; in scientific journal citation networks the most important seminal papers are increasingly cited; in transportation networks "all roads lead to Rome" and so forth. Probably more often, however, the very fact that nodes are highly linked may make them more "linkable" -- it is useful to fly through Chicago's O'Hare airport because so many other connecting flights already do; there may be reputational benefits to associating with "popular"

\footnotetext{
${ }^{29} I d$.
} 
people; popular sites garner more links on the World Wide Web. ${ }^{30}$ Once the concept of preferential attachment has been identified, it can provide insights into the growth of many different kinds of networks. While the particular reasons that well-connected nodes acquire additional links certainly vary from network to network, the general phenomenon of preferential attachment is widespread.

Though preferential attachment is common, in many real situations it is curtailed by cost or congestion. The capacity of a power hub limits the number of substations to which it can connect; the capacity of an airport limits the number of flights it can handle; popular people may run out of time or otherwise wish to limit their numbers of friends. Measuring the degree distribution of a network can thus lead to insights into how the network evolved. If the network is scale-free or very broad, one may search for some mechanism for preferential attachment. Similarly, if the number of connections cuts off at some point, a hunt for a congestion or cost mechanism may be warranted.

Citation networks, such as the patent network discussed in Part III of this Article or a network of scientific journal citations, tend to have very similar degree distributions, which are broad and skewed, but differ from the pure preferential attachment scale-free form. Figure 1 shows the distribution of number of citations received for the patent

\footnotetext{
30 The preferential attachment mechanism is related to the economic concept of "network effects" which explains, for example, why a lesser quality technology (such as VHS rather than Betamax for video recorders) can become entrenched. See, for a definition, S. J. Liebowitz, Stephen E. Margolis, Network Externalities (Effects), in THE NeW PALGRAVE's DictionARY OF ECONOMICS AND THE LAW (1998) Network effects can be a source of preferential attachment. People choose a particular technology because others have chosen it. "Network effects" are important causes of market failure and sub-optimal social outcomes. More generally, preferential attachment can lead to highly skewed outcomes even when attachments are selected entirely at random in the first instance. Disentangling pure preferential attachment ("the rich get richer") from the effects of underlying node quality ("the talented or hard-working get richer") is a difficult and open question in network science. Understanding the reasons for preferential attachment in a particular context may be very important in predicting or understanding the network's collective behavior.
} 
citation network at different times. It is quite broad -- there are many patents that have never been cited, but others that have received nearly 1000 citations. To look for possible scale-free behavior, we plot the distribution function on a "log-log" graph. On such a graph, a power-law decay would show up as a downward sloping straight line. (This is illustrated in Figure 4 at the bottom, which shows the power law distributions on a log-log graph.) The patent citation distribution is clearly quite broad and skewed, but the tail of the distribution is not quite a straight line on the graph. Instead, it curves downward, cutting off the probability of finding a patent that has received an extremely high number of citations.

While the precise mathematical form of these citation network distributions is not completely understood, our results -- discussed in more detail in Part III -- and those of others $^{31}$ suggest that the shape reflects a competition between preferential attachment -which leads to some patents acquiring very large numbers of citations -- and the rate at which patents age or "go out of date." The preferential attachment leads to a broad, skewed distribution, while the aging of nodes slows their accumulation of citations and "cuts off" the tail of the degree distribution. If a similar distribution is observed in some new network, it will be reasonable to predict that the growth of that network involved some mechanism for preferential attachment and for aging.

As more networks are characterized using a variety of metrics, it becomes possible to infer much about the means by which a particular network evolved (or is evolving) by measuring aspects of the network's current structure. It may conversely be

\footnotetext{
${ }^{31}$ See, e.g., S. N. Dorogovtsev and J. F. F. Mendes, Evolution of Networks with Aging of Sites, 62 PHYS. REV. E 1842-1845 (2000); Han Zhu, Xinran Wang, and Jian-Yang Zhu, Effect of Aging on Network Structure, 68 PHYS. REV. E 056121 (2003).
} 
possible to predict many aspects of the network structure that will result from particular linkage means of network growth.

\section{II.A.3 Network Structure and Collective Behavior}

The third task of network science is to understand the kinds of collective behavior that may emerge when elements of a network interact with one another and how the resulting behavior may depend upon the structure of the network. For example, the flow of information (or the progress of an epidemic) within a social group, the flow of oil through the ground, the susceptibility of an electrical or communication grid to the failure of individual elements, the cost of licensing the necessary patents to commercialize a particular technology, and the propagation and acceptance of a changing behavioral norm may all depend on the relational structure of an underlying network. ${ }^{32}$ Network science will attempt to delineate and interpret the common features of network structures and interactions between "nodes" that result in particular varieties of collective responses. Such understandings may be used to predict the collective effects of changes in network structure, changes in the interactions between neighboring elements, and changing global influences -- including changes in legal rules.

\section{II.B. Why Legal Scholars Should Care About Network Science}

In some sense, legal scholarship, in its descriptive form, is network science -- the study of how particular social, commercial, infrastructural, and other kinds of networks adapt and react to particular rules of interaction between "nodes" that might be individuals, corporations, communities, "things," or institutions. More than this, in fact, normative legal scholarship, legal policymaking, statutory legislation, and common law

${ }^{32}$ See BARABASI, supra note 2, WATTS, supra note 2 and MALCOLM GLADWELL, THE TIPPING PoINT (2000) for examples of situations in which the local structure of a network can determine the global behavior. 
jurisprudence are in some respects network engineering -- attempts to produce particular collective social responses by adjusting the interactions and incentives experienced by individual network elements. Of course, this observation is important (and not merely semantic) only if thinking about society as a network matters -- only if it tells us something different from what we have already gained from our existing conceptual frameworks.

There are good reasons to think that network analysis will matter in this way -and that it may matter a lot. Here we discuss three inter-related concepts highlighted by network science which may have broad impact on legal and policy analysis: 1) node heterogeneity; 2) the importance of network relational structure; and 3) the complicated relationship between local structure and interactions and global, collective behavior.

\section{II.B.1 The Implications of Heterogeneity}

Much of our legal doctrine and scholarship -- including much law and economics analysis -- depends implicitly, but heavily, on assumptions and predictions about average or "typical" behavior. Thus, in legal decision-making we rely on the "reasonable person" and the "person having ordinary skill in the art," we seek to deter the "typical" criminal; and we attempt to avoid confusing the "ordinary consumer." We predict the results of policy changes by considering the rational economic actor (or, perhaps, the "boundedly rational" economic actor ${ }^{33}$ ). All of these modes of analysis rely on an intuitive assumption that various traits, propensities, preferences, and so forth are distributed among the population according to a more or less "normal" distribution. In other words,

\footnotetext{
${ }^{33}$ See, e.g., Cass Sunstein, ed., BeHAVIORAL LAW AND ECONOMICS (2000) for an overview of the significance of bounded rationality.
} 
we assume that the average behavior is the most typical behavior and that extreme deviations from the typical are extremely rare -- and thus generally unimportant.

This assumption is reasonable for many purposes since many properties are distributed according to a normal distribution -- there are no hundred foot tall or one inch tall human beings, for example. However, network science provides us with a warning about unquestioning reliance on the typicality assumption. It points out that there are common examples of quantities -- such as the number of links to a node -- that are distributed in a highly skewed and very broad manner -- indeed, "scale free" or close to it. While we have always known that such broad, skewed distributions were possible, the study of networks, along with their societal ubiquity, brings us face-to-face with the fact that, at least in some contexts, highly skewed, scale free or nearly scale free, distributions are not only possible, but common and that taking account of the non-typical may be crucial. $^{34}$

As discussed above, if a network is "scale free" or nearly so, it is meaningless to talk about a "typical" node because the average node is not the most typical node -- and the most important nodes are likely neither average nor typical. As a result, social interventions, including legal rules, which are aimed at the "typical" member of a social group may be ineffective -- it may be necessary to consider a broad spectrum of characteristics to devise a workable rule.

Thus, the first lesson from network science is that legal analysis should consider the possibility of heterogeneity -- in some cases radical heterogeneity -- among network elements and environments. Indeed, the realization that a simple and common

\footnotetext{
${ }^{34}$ See Chris Anderson, The Long TAIL: Why the Future of Business Is SElling Less of More (2006) (for a popular discussion of the prospective effects of consumer heterogeneity on business
} 
mechanism like preferential attachment in a network can result in radical heterogeneity should motivate us to consider what other commonplace deviations from "typicality" may arise. ${ }^{35}$ Perhaps deviations from the normal distribution are not so "abnormal" after all.

Currently, there is no complete fundamental understanding of when "scale-free" distributions occur. Intuitively, however, it seems likely that these distributions are possible when "scale" is not strongly constrained by some form of cost. ${ }^{36}$ For example, the network of World Wide Web hyperlinks (which is relatively unconstrained by linkage costs) is approximately scale-free, whereas the railway system (which is constrained by the costs of building additional track "links") and the power grid (which is constrained by the cost of wiring and the loss of energy in transportation) are not. ${ }^{37}$ An observation of extreme heterogeneity should trigger an inquiry not only into its effects but also into its causes. It is conceivable, for example, that there is a relation between the well-known highly skewed distribution of values of technological innovations and a fundamental lack of proportionality between research investment and research result. If this (highly speculative) premise were correct, it might have important implications for the use of

\footnotetext{
${ }^{35}$ The statistical physics interest in scale-free distributions, for example, pre-dates network theory and stems from the observation of scale free behavior at phase transitions and in observations of "self-organized criticality." See, e.g., Per BaK, How Nature Works: The Science of Self-Organized Criticality (1999); P.C. Hohenberg and B. I. Halperin, Theory of Dynamic Critical Phenomena, 49 REvIEWs OF

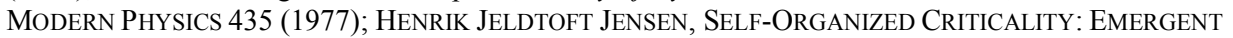
COMPLEX BeHAVIOR IN PhySiCAL AND BIOlogical Systems, Cambridge Lecture Notes in Physics (No. 10) (1998); Shang-Keng Ma, Modern Theory of Critical Phenomena, Frontiers in Physics (1976); H. Eugene Stanley, Introduction to Phase Transitions and Critical Phenomena (1971); H. Eugene Stanley, Scaling, Universality, and Renormalization: Three Pillars of Modern Critical Phenomena, 71 REV. MODERN PHYSICS S358 (1999).

${ }^{36}$ In statistical physics, for example, interest in scale-free phenomena arose in the study of critical phenomena. Critical points occur when energy and entropy balance in such a way that fluctuations on all length scales have equal free energy and thus all occur at once. Away from critical points, fluctuations in physical systems have a characteristic scale. See, e.g., D. Sornette, Critical PhENOMENA In NATURAL SCIENCES: ChaOs, Fractals, SElF-OrganiZATION AND DisORDER: CONCEPTS AND TOOLS (2d Ed. 2004) at 241-42 for a discussion of this point.

${ }^{37}$ See Newman, supra note 2 at 13-14.
} 
patent law to provide incentives to invest. Similarly, a very skewed distribution of network "connections" which results from some particular combination of legal rules and other norms and constraints might reflect an underlying skewed distribution of talent or effort, but we should recognition that preferential attachment alone is enough to produce such a distribution even if all nodes are identical. Depending on whether the skewed distribution of connections is socially desirable, this recognition may affect the choices of policies to pursue.

\section{II.B.2 The Importance of Local Relational Structure}

A second lesson from network science is the importance of network structure in determining collective behaviors, such as social norms and behavioral regularities, and flows of information, influence and other goods. Legal analysis often conceptualizes individual legal actors as responding independently to legal rules in the context of global average social forces. ${ }^{38}$ Network science demonstrates that collective behavior may be determined not only by the average impact of global social forces but also by the specific network structures by which these social forces are mediated. Social network studies demonstrate, for example, that access to information depends on one's position in the network. ${ }^{39}$ Similarly, statistical physics studies show that a randomly constructed network may make a transition from a set of disconnected clusters to a single connected network at a particular "critical" density of links. ${ }^{40}$ Diffusion of anything on a network -whether it be information, opinion, resources, or infection -- may thus be a complicated

\footnotetext{
38 This is the general approach of social norm theory, for example. See Richard H. McAdams \& Eric B. Rasmusen, Norms in Law and Economics, HANDBOOK OF LAW AND ECONOMICS (A. Mitchell Polinsky \& Steven Shavell eds., forthcoming 2006) for a recent review.

${ }^{39}$ See Strahilevitz, supra note 6 at 950-70, and references therein, discussing studies of information propagation in social networks.

${ }^{40}$ A scale-free network may or may not experience such a transition depending upon the precise form of the degree distribution and other factors. See Newman, supra note 2 at 38-41.
} 
function of the number and placement of network links. Depending on the specifics of relationships, for example, diffusion of information from one social group to another may be rapid or extremely slow. ${ }^{41}$

Rather than thinking of an individual person or firm as being immersed in an average social "ether" of information and influences, it may sometimes be important to take into account the specific local relationships in which particular individuals are embedded. Those specific local relationships and influences may affect collective behavior. The realization that a model in which an individual "particle" is subjected to the average influence of its fellows cannot always predict collective behavior was important in statistical physics -- it led to the rejection of "mean field theory" and inaugurated the modern study of collective physical phenomena. ${ }^{42}$ The statistical physics approach to network science stems from this background understanding, which may be quite important for legal analysis as well. ${ }^{43}$

\section{II.B.3 The Complicated Influence of Local Relationship Patterns on Collective Behavior}

Finally, and relatedly, network science recognizes that the global implications of particular local relationships are not always obvious from examining the local relationships in isolation. A simple example shown in Figure 5 illustrates the point.

\footnotetext{
${ }^{41}$ See Strahilevitz, supra note 6, arguing for a view of privacy that takes into account, based on social theory, the likelihood that information will diffuse out of a limited group to which it has been revealed.

${ }^{42}$ In statistical physics, the approximation that an individual atom reacts to the average influence of the other atoms is called "mean field theory." While mean field theory is very useful in some situations, it is particularly bad at explaining "phase transitions" (such as melting and freezing, evaporation, magnetization), in which the collective behavior of a system changes from one macroscopic state to another. Part of the reason for the failings of mean field theory is its inability to handle the "scale free" correlations between blocks of atoms of widely varying sizes that appear near many phase transitions. See, e.g., Ma, supra note 30 at 34-39, for a brief discussion of mean field theory and its shortcomings in the phase transition context.

${ }^{43}$ See Newman, supra note 2 and Albert and Barabasi, supra note 2, for discussions of the implications of local correlations for network structure.
} 
Assume that each dot represents an individual and that the associated + or - represents the individual's yes or no decision about some question. Also assume that each individual must make a decision and prefers, for some reason, to make the opposite decision from his or her immediate neighbors. (In physics this model is known as the "antiferromagnetic Ising model.") If the network of relationships between individuals forms a square pattern, as shown in Figure 5 at the top, every pair can be made happy by making opposing decisions, and the global arrangement will reflect the optimization of the pairwise interactions. However, if the network of relationships between individuals forms a triangular pattern, as shown in the bottom panel of Figure 5, it is simply not possible for everyone to disagree with all of his or her neighbors. Even though there is a preferred arrangement for every pair of neighbors (disagreement), the network as a whole will be unable to get to a completely "disagreeable" state. The network will be, in the terminology used by statistical physicists, "frustrated." 44 The best global arrangement is not predictable by optimizing the relative decisions of each pair. The collective behavior that results from the different relationship patterns is entirely different.

Figure 5 is just an illustration of the more general point that one cannot always predict global behavior from optimized interactions between pairs or in small groups. In the legal context, this insight suggests that focusing only on the efficiency of individual transactions between individual legal actors may, in some cases, lead to suboptimal legal policies because these actors are embedded in a network of relationships. Yet legal analysis and implementation frequently does focus on such individual transactions, either

\footnotetext{
${ }^{44}$ See, e.g., SORNETTE, supra note 31 at 441-43, for a discussion of this example of frustration.
} 
because legal rules are forged in the context of specific disputes or because, as a theoretical matter, generalizing beyond these individual transactions is difficult. ${ }^{45}$

Merely recognizing these conceptual points may sometimes be enough to provide insight into an important legal question. ${ }^{46}$ However, network science's potential usefulness to legal analysis extends beyond highlighting these general concepts. Indeed, the observations that important social and economic quantities may be distributed in a highly skewed, scale-free manner and the idea that collective behavior may not be accurately predictable by focusing either on average global influences or on individual transactions are not entirely new. Legal scholars and decision makers have employed the approximations of typicality, of average social forces, or of the generalizability of pairwise interactions in the past not because they were unaware that reality is more complicated but as means to reduce the complexity of the analysis.

The potential contribution of network science is that it not only highlights these conceptual issues, but also promises to provide ways to determine when these issues are likely to be important and tools to perform more accurate analyses in various contexts. These tools may be analytical, such as the introduction of explanatory concepts like "preferential attachment" and "small worlds." They may be mathematical, as illustrated by the analysis of patent citations in Part III of this Article. Or they may be

\footnotetext{
${ }^{45}$ For example, applications of game theory to legal theory very frequently focus on analyzing a twoperson or, at most, three-person game and then extrapolate to predictions about collective behavior. See, generally, DOUGLAS G. BAIRD et al., GAME THEORY AND THE LAW 33 (1994) and ROBERT COOTER AND THOMAS UlEN, LAW AND ECONOMICS $\left(4^{\text {th }}\right.$ Ed. 2003$)$ for examples of applying game theory to legal issues. Probably the most famous example of this approach in the law is the classic Prisoner's Dilemma game (cited in more than 2000 articles in the LEXIS law review database), which is often used to explain problems of collective action and free riding. But see Tom Ginsburg and Richard H. McAdams, 45 WM AND MARY L. REV. 1229 (2004), arguing, in the context of international relations, that the Prisoner's Dilemma game is overused in comparison to games involving motives for cooperation.

${ }^{46}$ See Strahilevitz, supra note 6 and Ayres and Baker, supra note 6.
} 
computational, as exemplified by many social network theory software tools or by the computer simulation methods of statistical physics. ${ }^{47}$

Network science concepts may be used as a basis for critiquing extant or proposed legal rules. ${ }^{48}$ Network science methods may also provide, as we begin to demonstrate in Parts III and IV of this Article, means of empirical analysis that are applicable to legally significant systems in which heterogeneity and network structure are important. Network science techniques may also be used to model the collective behavior that results from particular local interactions and preferences and to predict whether legal changes will lead to global behavioral change. For example, one may begin by postulating particular pairwise interactions, such as those embodied in many law and economics game theory models. Network science methods may then be employed to determine the collective behavior that results from such pairwise interactions. ${ }^{49}$ Computer simulations will often

\footnotetext{
${ }^{47}$ See, e.g., CARRINGTON ET AL., supra note 2, describing social network methodologies; and www.insna.org, the website of the International Network for Social Network Analysis, which provides descriptions of and links to numerous social network software packages. See, e.g., http://sip.clarku.edu, maintained by Harvey Gould and Jan Tobochnik, for resources and links about simulation methods in physics.

${ }^{48}$ See, e.g., Ayres and Baker, supra note 6; Strahilevitz, supra note 6; Matwyshyn, supra note 6.

${ }^{49}$ While the Prisoner's Dilemma paints a rather gloomy, non-cooperative view of the social world, simulations of iterated prisoner's dilemmas on networks of various structures with various strategic rules are beginning to offer a much more complex and varied view of the possible cooperative and noncooperative outcomes of the game. See, e.g., Guillermo Abramson and Marcelo Kuperman, Social Games in a Social Network, 63 PHYS. REV. E 030901(R) (2001); Beom Jun Kim, Ala Trusina, Petter Holme, Petter Minnhagen, Jean S. Chung, and M. Y. Choi, Dynamic Instabilities Induced By Asymmetric Influence: Prisoners' Dilemma Game in Small-World Networks, 66 PHYS. REV. E 021907 (2002); Y. F. Lim, Kan Chen and C. Jayaprakash, Scale-Invariant Behavior in a Spatial Game of Prisoners' Dilemma, 65 PhYs. ReV. E 026134 (2002); Zhi-Xi Wu, Xin-Jian Xu, Yong Chen, and Ying-Hai Wang, Spatial Prisoner's Dilemma Game with Volunteering in Newman-Watts Small-World Networks, 71 PHYs. REV. E 037103 (2005); Petter Holme, Ala Trusina, Beom Jun Kim and Petter Minnhagen, Prisoners' Dilemma in Real-World Acquaintance Networks: Spikes and Quasiequilibria induced by the Interplay Between Structure and Dynamics, 68 PHYs. REV. E 030901(R) (2003). Other strategic games are also being explored on networks using statistical physics approaches. See, e.g., Ping-Ping Li, Da-Fang Zheng, and P. M. Hui, Dynamics of Opinion Formation in a Small-World Network, arXiv:physics/0510065 v1 (October 10, 2005); Sitabhra Sinha and Sudeshna Sinha, Robust Emergent Activity in Dynamical Networks, arXiv:cond-mat/0510603 v1 (October 22, 2005); J. C. Gonz'alez-Avella, M. G. Cosenza, and K. Tucci, Nonequilibrium Transition Induced by Mass Media in a Model for Social Influence, arXiv:nlin.AO/0511013 v1 (November 8, 2005).
} 
be the most feasible approach to such questions and can in principle be devised to account for heterogeneous preferences and for various network structures.

Just as has been done with game theory models, it may well be possible to map some problems of legal significance onto models that have already been studied by physicists, sociologists, and other network scientists. Additionally, legal problems may eventually motivate network scientists to perform computer simulations or mathematical studies of models derived from those problems.

In sum, network science is an emerging discipline that holds great promise to provide insights, tools, and models that will make important contributions to legal analysis. In the next Part we provide a sample of the application of network science to law by investigating what the evolution of the patent citation network can tell us about how the standard of patentability is changing.

\section{NETWORK CLUES TO A DECREASING PATENTABILITY STANDARD}

We now move from the lofty realms of possibility to a specific application of network science in the legal arena. We have performed a quantitative analysis of United States patents and their citations, treating the patents as citation "nodes" and citations from one patent to another as network "links." Our analysis suggests that the "patent explosion" of recent years is not completely explained by either a rapidly increasing pace of technological advance or a broadened scope of patented technology. Something "more" has happened in the network -- an increasing stratification of patent "citability," by which we mean the probability that a patent with particular characteristics will be cited. In this Part we describe how our network science approach reveals this dynamic change and hypothesize that it may have been the result of a decreasing patentability 
standard. We distinguish carefully between our empirical results -- which any theory of the way in which patents and the citations between them have evolved will need to explain -- and our proposed interpretation, which is, of course, open to debate. A brief technical report focusing on the methodological contributions of this research to network science has been accepted for publication in the physics journal, Physica A. ${ }^{50}$

\section{III.A. Background}

\section{III.A.1 The Patent System and Its Discontents ${ }^{51}$}

Recent years have seen a major upsurge in patenting, an expansion of the range of innovations which are eligible for patent protection, and a perception that the United States economy relies more and more heavily on knowledge and innovation for its success. (See Figure 6, showing the number of patents issued on linear and semi-log scales.) At the same time, developments in the law, including the establishment of a single appellate court -- the Federal Circuit Court of Appeals -- to hear the vast majority of patent appeals in the United States, have led to debate as to whether the legal system is becoming increasingly "patent-friendly;" whether patents are being issued for lower quality innovations; and whether the legal rights awarded to patentees are becoming stronger. ${ }^{52}$ Along with empirical evidence that increasingly raises questions as to the

\footnotetext{
${ }^{50}$ Gábor Csárdi, Katherine Strandburg, László Zalányi, Jan Tobochnik, and Péter Érdi, Modeling Innovation by a Kinetic Description of the Patent Citation System, PHYSICA A (forthcoming 2006).

${ }^{51}$ The title of this section is borrowed from a recent book by two well-known economists of innovation which exemplifies the kinds of criticisms of the patent system which have become prevalent in recent years. JAFFE AND LERNER, supra note 8.

52 For a sample of the many discussions of these issues see, e.g., David E. Adelman, A Fallacy of the Commons in Biotech Patent Policy, 20 BERKELEY TeCH. L.J. 985 (2005); Adelman and DeAngelis, supra note 17; John R. Allison and Mark A. Lemley, The Growing Complexity of the United States Patent System, 82 Boston UnIV. L. ReV. 77 (2002); Dan L. Burk and Mark A. Lemley, Policy Levers in Patent Law, 79 VA. L. REV. 101 (2003); Dan L. Burk and Mark A. Lemley, Designing Optimal Software Patents, in INTELLECTUAL PROPERTY Rights In FRONTIER INDUSTRIES: SOFTWARE AND BIOTECHNOLOGY, Robert Hahn, ed., (2005); Wesley M. Cohen and Stephen A. Merrill, Eds., PATENTS IN THE KNOWLEDGE-BASED ECONOMY, National Research Council of the National Academies (2003); Christopher A. Cotropia, The Suggestion Test as a Rule of Evidence in Patent Law, available at
} 
extent to which patents are needed to provide incentives for research and development, ${ }^{53}$ these trends have converged to raise growing concerns among academics and policymakers about whether patent law and policy are adequately designed to "promote the Progress of ... useful Arts." ${ }^{44}$ This discontent has gained the attention of members of Congress, who have proposed various patent reform bills, ${ }^{55}$ of the Federal Trade Commission, ${ }^{56}$ of the National Academies of Sciences, ${ }^{57}$ and of the Supreme Court, which has granted review in six patent cases since $2005^{58}$-- a level of Supreme Court interest

http://www.chicagoip.com/CotropiaSuggestionTestDRAFT.pdf (2006); Rochelle Cooper Dreyfuss, The Federal Circuit: A Case Study in Specialized Courts, 64 N. Y. U. L. REV. 1 (1989); Rochelle Cooper Dreyfuss, The Federal Circuit: A Continuing Experiment in Specialization, 54 CASE WESTERN RES. L. REV. 769 (2004); Federal Trade Commission, supra note 8; Bronwyn H. Hall, Exploring the Patent Explosion, 30 J. TECH. TRANSFER 35-48 (2005); Heller and Eisenberg, supra note 8; JAFFE AND LERNER, supra note 8; Jay P. Kesan, Carrots and Sticks to Create a Better Patent System, 17 BERKELEY TECH. L.J. 763 (2002); William M. Landes and Richard A. Posner, An Empirical Analysis of the Patent Court, 71 U. ChICAgo L. ReV. 111 (2004); Allan N. Litmann, Restoring the Balance of Our Patent System, 37 IDEA 545 (1997); Glynn S. Lunney, Jr., E-Obviousness, 7 Mich. Telecomm. TeCH. L. ReV. 363 (2000 / 2001); Ronald J. Mann, The Myth of the Software Patent Thicket: An Empirical Investigation of the Relationship Between Intellectual Property and Innovation in Software Firms, 83 TEXAS L. REV. 961 (2005); Gregory N. Mandel, Patently Non-Obvious: Empirical Demonstration that the Hindsight Bias Renders Patent Decisionmaking Irrational, available at: www.ssrn.com/abstract=871684 (2005); Robert P. Merges, As Many as Six Impossible Patents Before Breakfast: Property Rights for Business Concepts and Patent System Reform, 14 BeRKeley TeCH L.J. 577 (1999); Robert P. Merges and Richard R. Nelson, On the Complex Economics of Patent Scope, 90 Columbia L. Rev. 839 (1990); Robert P. Merges, One Hundred Years of Solicitude: Intellectual Property Law, 1900-2000, 88 CAL. L. REV. 2187 (2000); Merrill et al., supra note 8; Arti K. Rai, Allocating Power Over Fact-Finding in the Patent System, 19 BERKELEY TECH. L. J. 907 (2004); Arti K. Rai, Engaging Facts And Policy: A Multi-Institutional Approach To Patent System Reform, 103 Columbia L. REV. 1035 (2003); Carl Shapiro, Navigating the Patent Thicket: Cross Licenses, Patent Pools, and Standard-Setting in InNOVATIOn Policy AND THE ECONOMY, Volume I, Adam Jaffe, Joshua Lerner, and Scott Stern, eds., MIT Press (2001); John R. Thomas, Formalism At The Federal Circuit, 52 Amer. U. L. ReV. 771 (2003); John L. Turner, In Defense of the Patent Friendly Court Hypothesis: Theory and Evidence (2005), at http://www.terry.uga.edu/ jlturner/PatentFCH.pdf.

53 See, e.g., James Bessen and Michael J. Meurer, Lessons For Patent Policy From Empirical Research On Patent Litigation, 9 LEWIS \& CLARK LAW REVIEW 1, 6-8 (2005) (reviewing empirical evidence for the relatively small size of the "patent premium"); Wesley M. Cohen et al., Protecting Their Intellectual Assets: Appropriability Conditions and Why U.S. Manufacturing Firms Patent (or Not), NBER Working Paper 7552 (2000); Bronwyn Hall \& Rosemarie Ziedonis, The Patent Paradox Revisited: An Empirical Study of Patenting in the U.S. Semiconductor Industry, 1979-1995, 32 RAND J. ECON. 101 (2001).

${ }_{55}^{54}$ U.S. Const., Art. I, sec. 8.

${ }^{55}$ See, e.g., H.R. 2795, Patent Reform Act of 2005; S3818, Patent Reform Act of 2006.

${ }_{57}^{56}$ Federal Trade Commission, supra note 8.

${ }_{58}^{57}$ Merrill et al., supra note 8.

${ }^{58}$ See cases supra note 10. 
unheard of in at least 25 years. It has also provoked responses from defenders of the present system, who argue that criticisms are overblown. ${ }^{59}$

To accomplish its constitutionally mandated objective, patent protection must be carefully tailored to balance its benefits (which may include providing incentives to invent, functioning as a signal of technical competence, and facilitating a market for intangible knowledge) against its costs. Because a patent provides exclusive rights to practice the patented technology, the costs that patents impose on society may include not only supra-competitive pricing of patented products but also increased barriers to building upon existing technology. These costs arise because improving upon a patented technology may require either using the patented technology during development or incorporating it into the improved result. In either case, United States law generally requires that the improver obtain a license from the holder of a patent on the foundational technology (or technologies, as is often the case). Such licenses usually require the payment of royalties. Negotiating authorization to build upon a patented technology can be expensive, especially when there is disagreement as to the relative value of various contributions to the improved technology. In the extreme case, when the holders of the original patent and an improvement patent cannot agree on a licensing arrangement, this "blocking patent" situation can deprive the public of access to the improved technology altogether.

Part of the patent cost-benefit analysis is a requirement that patents be issued only for inventions that are "novel" and "nonobvious"60 -- sufficiently different from presently available technology to justify an award of legal exclusivity to the inventor. The legal

${ }^{59}$ See supra note 11; see also, e.g., W. Lesser \& Travers Lybbert, Do Patents Come Too Easy?, 44 IDEA 381 (2004); Mandel, supra note 46; Adelman, supra note 46; Adelman and DeAngelis, supra note 17. ${ }^{60}$ See 35 U.S.C. $\S \S 101-103$. 
standard of nonobviousness sets the height of the bar for "sufficient" difference. Along with other patentability requirements, it determines the tradeoff between social costs and benefits that results from the issuance of a patent. Because patents can impose substantial costs on consumers and subsequent innovators, one major objective of studies of the patent system is to determine whether the procedures and substantive standards that guide the issuance of patents are appropriately tuned.

Recent developments in the law, along with the issuance of a burgeoning number of patents, have led to widespread perceptions among patent law scholars and policymakers that the system is off balance. ${ }^{61}$ It is argued, for example, that the legal standard of nonobviousness is insufficiently rigorous; ${ }^{62}$ that patent examiners have insufficient access to potentially relevant prior art in some fields such as software or business methods; ${ }^{63}$ and that patents issue on increasingly upstream technologies that form the basis for further advances. ${ }^{64}$ There are dire predictions of a patent "thicket," ${ }^{, 65}$ in which technological progress is made increasingly difficult by the need to negotiate multiple levels of "blocking patent" rights on each of the many patented components which may be needed to produce a new commercial product. ${ }^{66}$ One way to avoid a potential thicket is for competing patent holders to negotiate cross-licenses or "patent pools." Such agreements between competitors raise concerns about collusion, however,

${ }^{61}$ See, e.g., references, supra note 8.

${ }^{62}$ See, e.g., Federal Trade Commission, supra note 8; Merrill et al., supra note 8; Br. Of Intellectual Property Law Professors as Amici Curiae in Support of Petitioner, KSR Int'l Co. v. Teleflex, Inc., No. 041350 (U.S. Supreme Court, 2006) and references therein. But see Cotropia, supra note 46 (Federal Circuit "suggestion test" application is tailored to the complexity of the underlying technology) and Mandel, supra note 46, (empirical evidence that hindsight bias is likely to result in unwarranted findings of obviousness).

${ }^{63}$ See, e.g. JAFFE AND LERNER, supra note 8 at 198-202.

${ }^{64}$ See, e.g., Federal Trade Commission, supra note 8 , and references therein.

${ }^{65}$ See, e.g., Shapiro, supra note 46; James Bessen, Patent Thickets: Strategic Patenting of Complex Technologies, Working Paper, available at http://www.researchoninnovation.org/thicket.pdf; but see Mann, supra note 46; Adelman, supra note 46; Adelman and DeAngelis, supra note 17.

${ }^{66}$ See, e.g., Robert C. Merges, Intellectual Property Rights and Bargaining Breakdown: The Case of Blocking Patents, 62 TENN. L. REV. 75 (1994). 
and the societal ramifications depend upon the extent to which cross-licensing lowers barriers to the use of complementary technologies (as opposed to allowing competitors to avoid competition from substitute technologies). ${ }^{67}$

Understanding the interaction between innovation and the patent system is a difficult job for many reasons. Increased patenting, for example, can stem from various causes, including an increased pace of technological change, an increased range of patented technology due either to expansion of the scope of legally patentable subject matter or to the birth of new fields of technology, a growing perception of the usefulness of patents as business tools, or the issuance of lower quality patents. Empirical investigation of the patent system can play an important role in understanding how to maintain the appropriate balance. In what follows we report the results of a detailed study of the evolution of the patent citation network and argue that the evolution suggests that the patentability standard has been decreasing. Before presenting our results, we detour to provide an overview of patent issuance and the meaning of patent citations and discuss how patent data has been used in previous studies. With that context in place, we then describe our study.

\section{III.A.2 Patent Issuance and Prior Art Citations}

United States patents are issued by the Patent and Trademark Office (USPTO) after applications are examined to determine, among other things, whether the patent "claims" meet the legal requirements of novelty and non-obviousness. ${ }^{68}$ Patent claims are specific statements of the scope of the legal coverage of a patent. As noted above, the

\footnotetext{
${ }^{67}$ See, e.g., Gilbert Goller, Competing, Complementary and Blocking Patents: Their Role in Determining Antitrust Violations in the Areas of Cross-Licensing, Patent Pooling and Package Licensing, 50 J. PAT. OFF. SoC'Y 723 (1968); see also Federal Trade Commission, supra note 8.

${ }^{68}$ See 35 U.S.C. $\S \S 102,103$, and 112 for the main statutory requirements for patentability; see also MPEP.
} 
legal effect of a patent is to provide the patentee a right to exclude others from using the claimed technology without a license, as detailed in the infringement provisions of the patent statute. $^{69}$

In the course of the examination of a patent application for novelty and nonobviousness, patent claims are compared against potential "prior art," consisting in large part of prior patents and other publications in relevant technical fields. Potential prior art is identified by applicants and their patent attorneys and by the official patent examiners. To obtain a patent, the claimed invention must be "novel," meaning there is no prior patent or other "prior art" that is identical to what is claimed. More importantly, the claimed invention must be nonobvious, meaning that at the time it was invented, the invention would not have been obvious to a "person having ordinary skill in the art" in the field of the invention. When an invention is deemed obvious, it is usually because it is an obvious combination of prior art technology. Determining whether a combination of prior technology would have been obvious is a tricky matter, since it requires an exercise in hindsight and an exercise in putting oneself in the shoes of the skilled practitioner of the patented technology. ${ }^{70}$ The way in which obviousness is determined essentially sets the threshold of patentability.

To guide this endeavor, and to try to avoid hindsight bias, the Federal Circuit Court of Appeals employs a controversial test. Under this "suggestion test," a patent examiner may not reject a patent application as an obvious combination of prior art elements unless a "suggestion, teaching, or motivation to combine" the prior art elements

${ }^{69}$ See 35 U.S.C. \$ 271.

${ }^{70}$ See, e.g., Mandel, supra note 52; Rebecca S. Eisenberg, Obvious to Whom? Evaluating Inventions from the Perspective of the PHOSITA, 19 BERKELEY TECH. L. J. 885 (2004); Cyril A. Soans, Some Absurd Presumptions in Patent Cases, 10 IDEA 433, 438 (1966) (coining the name "Mr. PHOSITA"). 
can be found "1) in the prior art references themselves; 2) in the knowledge of those of ordinary skill in the art that certain references ... are of special interest or importance in the field; or 3) from the nature of the problem to be solved, leading inventors to look to references relating to possible solutions to that problem."71 The test has been widely, though certainly not universally, criticized as lowering the barrier to patenting of obvious combinations of or improvements on old technology $y^{72}$ and is pending review by the Supreme Court. ${ }^{73}$

Seeking out prior art patents (and other sources of prior art) is key to determining both novelty and nonobviousness. The search for related prior patents is guided to a significant extent by an ad hoc classification scheme that has been developed by the USPTO over the years. ${ }^{74}$ References are cited in the issued patent document if their technical relationship to the claimed technology is close enough that they are relevant to determining whether the claimed technology is new and nonobvious. ${ }^{75}$ Recent studies show that patent examiners provide a large fraction of the cited references. During the 2001-2003 period, for example, examiners provided 67 per cent of all citations. Indeed,

\footnotetext{
${ }^{71}$ Teleflex, Inc. v. KSR International Co., 119 Fed. Appx. 282, 2005 U.S. App. LEXIS 176 at*7-*8 (unpublished, Fed. Cir. January 6, 2005), citing Ruiz v. A.B. Chance Co., 234 F.3d 654, 665 (Fed. Cir. 2000).

${ }^{72}$ See, e.g., Robert P. Merges, Uncertainty and the Standard of Patentability, 7 HIGH TECH. L. J. 1 (1993); Lunney, supra note 46; John H. Barton, Non-Obviousness, 43 IDEA 475 (2003); Br. Of Twenty-Four Intellectual Property Law Professors as Amici Curiae in Support of Petitioner, KSR Int'l Co. v. Teleflex, Inc., No. 04-1350 (U.S. Supreme Court, 2005). But see, e.g., Cotropia, supra note 46, arguing that the Federal Circuit has not applied a "narrow" version of the suggestion test, but has tailored the test to the complexity of the technology.

${ }^{73}$ KSR Int'l Co. v. Teleflex, Inc., Case No. 04-1350 (cert granted, June 26, 2006. See also Crouch, Dennis, Solicitor General to Opine on Landmark Obviousness Case, Patently-O Blog, available at http://patentlaw.typepad.com (October 4, 2005) and associated linked documents, including amicus briefs taking a variety of positions regarding the "suggestion test" issue.

${ }^{74}$ See USPTO MANUAL OF PATENT ClASSIFICATION, available at http://www.uspto.gov/web/patents/classification.

${ }^{75}$ See MPEP $§ 707.05$.
} 
in 40 per cent of the patents granted all citations were provided by examiners. ${ }^{76}$ Because such a large fraction of references are provided by patent examiners, and another large group by patent attorneys, citations do not necessarily indicate a direct flow of knowledge and thus we treat them only as indications of technological relationships.

Patents and their citations form a directed network (meaning that citations go from later patents to earlier patents and not in the opposite direction) in which patents are the network "nodes" and citations are directed "links." Citations convey valuable information about the relationships between the technologies covered by the citing and cited patents. The patent citation network thus can be viewed as a kind of map of the space of patented technology, indicating the relationships between various pieces of "property" in that space. ${ }^{77}$ As discussed in Part III.B, the evolution of the network may help to illuminate whether patents are being awarded for more trivial technological steps.

While the precise significance of a patent citation varies, a citation sometimes indicates that the claims of the cited patent encompass the claims of the citing patent and that a "blocking patent" situation exists so that permission from both patent owners is needed in order to use the invention claimed in the citing patent. As will be discussed in Part V, we believe it is likely that the structure of the patent citation "map" can be mined for signatures of patent "thickets," in which there is a high density of overlapping patent claims, so as to test, for example, whether such "thickets" are increasingly prevalent in the patent system.

\footnotetext{
${ }^{76}$ Juan Alcacer and Michelle Gittelman, How Do I Know What You Know? Patent Examiners and the Generation of Patent Citations, available at http://ssrn.com/abstract=548003, (2004).

${ }^{77}$ Of course, this map is neither perfect nor complete. Examiners and applicants may miss relevant connections between patents, cite particular patents because they are familiar, and so forth. The analysis here assumes only that citations generally indicate technological relationships between citing and cited patents.
} 


\section{III.A.3 Relationship of this Study to Previous Uses of Patent Citation Data}

The United States patent system provides a historical record that encompasses much of the history of innovation in this country and, increasingly, abroad. Records of patent prosecution, patent citations, and patent litigation over many years are publicly available. The history provided by patent records is incomplete, of course. Many technical advances are either unpatented trade secrets or unpatentable technical knowhow. Historically, moreover, the patent record was limited to traditionally "industrial" innovations, though the scope of patentable subject matter has expanded to cover an increasingly broad range of innovations at an increasingly early stage of development. Whatever its limitations, the patent record has long been recognized as a rich source of data about innovation and innovation policy. ${ }^{78}$ In the past, the form in which the data were available made quantitative analysis a difficult and painstaking process and limited the kinds of analyses that could be performed. Recent advances in computer technology, however, along with the efforts of empirical economists have rendered a wealth of patent data suitable for large-scale quantitative analysis. ${ }^{79}$

A surge of attempts by economists, social scientists, and legal academics to capitalize on this new availability has resulted. ${ }^{80}$ For the most part, that work has applied

\footnotetext{
${ }^{78}$ See, e.g., Griliches, Zvi, Patent Statistics as Economic Indicators: A Survey, 28 Journal OF ECONOMIC Literature 1661-1707 (1990); Trajtenberg, Manuel, A Penny for your Quotes: Patent Citations and the Value of Innovations, 21 RAND J. ECON. 172 (1990).

${ }^{79}$ See especially Bronwyn H. Hall, Adam B. Jaffe and Manuel Trajtenberg, The NBER Patent Citation Data File: Lessons, Insights and Methodological Tools, in Adam B. Jaffe and Manuel Trajtenberg, eds., PATENTS, CitATions, \& InNOVATIONS: A Window ON THE KNOWLEDGE ECONOMY, MIT Press (2003).

${ }^{80}$ See, e.g., Allison et al., supra note 17; Adelman and DeAngelis, supra note 17; Bessen and Meurer, supra note 47; Emmanuel Duguet and Megan MacGarvie, How Well Do Patent Citations Measure Flows of Technology? Evidence from French Innovation Surveys, 14 ECON. OF INNOVATION AND NEW TECH. 374 (2005); Lee Fleming, Adam Juda, and Charles King III, Small Worlds and Regional Innovative Advantage, Harvard Business School Working Paper Series, No. 04-008 (2003); Lee Fleming, Recombinant Uncertainty in Technological Search, 47 MGM'T SCIENCE 117 (2001); Lee Fleming and Olav Sorenson, Technology as a Complex Adaptive System: Evidence from Patent Data, 30 RESEARCH POL'Y 1019 (2001); John Hagedoorn and Myriam Cloodt, Measuring Innovative Performance: Is There an Advantage in Using
} 
statistical regression techniques to connect patent characteristics -- such as the number of citations made and received, the number of patent claims and whether the patent was renewed; inventor characteristics -- such as geographical location and employment context; and, most recently, patent examiner characteristics -- such as length of experience -- to financial, economic and technological indicators. In this way, patent data has been used to investigate knowledge flows and spillovers; ${ }^{81}$ to attempt to determine the characteristics of valuable patents; ${ }^{82}$ and to try to understand the role innovation plays

Multiple Indicators?, 32 RESEARCH POL'Y 1365 (2003); Hall and Ziedonis, supra note 47; Hall, supra note 46, 30 J. TeCh. Transfer 35 (2005); D. Harhoff, F. Narin, F.M. Scherer, and K. Vopel, Citation Frequency and the Value of Patented Inventions, 81 REV. ECON. AND STATISTICS 511 (1998); Dietmar Harhoff, Frederic M. Scherer, and Katrin Vopel, Citations, Family Size, Opposition and the Value of Patent Rights, 32 ReSEARCH PoL'Y 1343 (2003); Zan Huang, Hsinchun Chen, Alan Yip, Gavin Ng, Fei Guo, Zhi-Kai Chen, and Mihail C. Roco, Longitudinal Patent Analysis for Nanoscale Science and Engineering: Country, Institution and Technology Field, 5 J. NANOPARTIClE Res. 333 (2003); Adam B. Jaffe and Manuel Trajtenberg, eds., PATENTS, CitATIONS, \& InNOVATIONS: A Window ON THE KNOWLEDGE ECONOMY (2003); Jean O. Lanjouw and Mark Schankerman, Patent Quality And Research Productivity: Measuring Innovation with Multiple Indicators, 114 Econ. J. 441 (Royal Economic Society 2004); Alan C. Marco, The Option Value of Patent Litigation: Theory and Evidence, 14 REV. FinANCIAL ECON. 323 (2005); Alan C. Marco, Strategic Patent Extension in Pharmaceuticals: Evidence from Patent and Pricing Data, American Law and Economics Association Conference, New York (May 2005), available at http://irving.vassar.edu/faculty/am/Papers/drugs05.pdf; Alan C. Marco, Dynamics of Patent Citations, preprint (2005); Per Botolf Maurseth, Lovely but Dangerous: The Impact of Patent Citations on Patent Renewal, 14 Economics of InNOvation And New Technologies 351-74 (2005); Kimberly A. Moore, Worthless Patents, 20 Berkeley TeCH. L.J. 1521 (2005); Bhaven N. Sampat, Examining Patent Examination: An Analysis of Examiner and Application Generated Prior Art, Working Paper, Prepared for NBER Summer Institute (2004); Bhaven N. Sampat and Arvids A. Ziedonis, Cite Seeing: Patent Citations and Economic Value, Working Paper (2002); Gerald Silverberg and Bart Verspagen, The Size Distribution of Innovations Revisited: An Application of Extreme Value Statistics to Citation and Value Measures of Patent Significance, ECIS Working Papers 04.17 (2004); Olav Sorenson, Jan W. Rivkin, and Lee Fleming, Complexity, Networks and Knowledge Flow, Harvard Business School Working Paper, No. 04-027 (2003); Deborah Strumsky, Jose Lobo, and Lee Fleming, Metropolitan Patenting, Inventor Agglomeration and Social Networks: A Tale of Two Effects, Los Alamos National Laboratory Technical Report LAUR-048798 (2005); Iwan von Wartburg, Thorsten Teichert, and Katja Rost, Inventive Progress Measured by Multi-Stage Patent Citation Analysis, 34 RES. POL'Y 1591 (2005); Arvids Ziedonis and Bhaven N. Sampat, Patent Citations and the Economic Value of Patents: A Preliminary Assessment, in HANDBOOK OF QuAntitative Science AND TeChNOlOGY ReSEARCH, Henk Moed, Wolfgang Glänzel, and Ulrich Schmoch, eds., Kluwer Academic Publishers (2004).

${ }^{81}$ See, e.g., Duguet and MacGarvie, supra note 73; Fleming, Juda, and King. supra note 73; Jaffe and Trajtenberg, supra note 73; Olav Sorenson, Jan W. Rivkin, and Lee Fleming, Complexity, Networks and Knowledge Flow, Harvard Business School Working Paper, No. 04-027 (2003); Deborah Strumsky, Jose Lobo, and Lee Fleming, Metropolitan Patenting, Inventor Agglomeration and Social Networks: A Tale of Two Effects, Los Alamos National Laboratory Technical Report LAUR-04-8798 (2005)

${ }^{82}$ Allison et al, supra note 17; Bessen and Meurer, supra note 47; Hagedoorn and Cloodt, supra note 73; Harhoff,, et al. (1998), supra note 73; Harhoff, Scherer, and Vopel, supra note 73; Jaffe and Trajtenberg, 
in the behavior of various types of institutions, from universities to small and large firms. $^{83}$

Because of its heterogeneity and local structure, the network of patents and citations is a much richer source of information about the patent system and the associated technological development than is generally captured by these techniques. Network science analysis of the patent citation network has great potential both to complement existing econometric studies of patent citations and to advance the understanding of networks in general because of the fact that the patent citation network is one of the largest and most completely characterized networks available for study.

Though legal scholars and economists have generally not employed a network approach, ${ }^{84}$ a few studies of innovation by social scientists have applied social network analysis techniques to patent data. These studies, some of which are described in a bit more detail in Part IV, view patents as "footprints" of innovation. They interpret the pattern of patent citations to indicate the combination of past technologies into new innovations and use the patent citation network to investigate theories of innovation as recombinant search. ${ }^{85}$ These theories of innovation should be of interest to legal scholars since they move beyond a linear model of sequential or cumulative innovation and attempt to use network concepts and measures to incorporate some of the complexities of the innovative process. Dealing with inventive combinations is a critical and ill-

\footnotetext{
supra note 73; Lanjouw and Schankerman, supra note 73; Moore, supra note 73; Sampat and Ziedonis, supra note 73; Ziedonis and Sampat, supra note 73.

${ }^{83}$ See, e.g., Fleming, Juda, and King, supra note 73; Hall and Ziedonis, supra note 47; Huang et al., supra note 73; Jaffe and Trajtenberg, supra note 73.

${ }^{84}$ A notable exception is the work of Prof. Gavin Clarkson, who is employing a network density metric to investigate patent pools. See supra note 6.

${ }^{85}$ Fleming, supra note 73; Fleming and Sorenson, supra note 73.
} 
understood aspect of patent law, as demonstrated by the difficulty in finding an effective approach to nonobviousness.

Our treatment of patent citations also differs from that of a number of previous studies because we attempt to make minimal assumptions about the significance of individual citations. Many previous studies have assumed that when a patent cites another patent it is an indication of knowledge flow from the cited patent to the inventors of the citing patent. ${ }^{86}$ This assumption is questionable in light of data, only recently available in electronic form, showing the extent to which citations are inserted, not by the patent applicant (or even by the applicant's attorneys), but by patent examiners long after the time of invention. ${ }^{87}$ Our approach to patent citations is parsimonious and limited to an assumption that citations generally indicate significant technological relationships between patented technologies. We do not attempt to probe knowledge flows.

Finally, this study differs from many econometric studies because we make no assumptions about the distribution or functional form that describes the citation data. Econometric studies using patent data have been criticized due to their reliance on implicit assumptions about the distribution of citation data that may affect the analysis. ${ }^{88}$ As already mentioned, citation data is highly skewed and far from the "normal distributions" which are typically used in statistical analysis. Thus, particular care must be taken in interpreting those econometric analyses. ${ }^{89}$ Network science approaches avoid

\footnotetext{
${ }^{86}$ See, e.g., many of the studies collected in Jaffe and Trajtenberg, supra note 73.

${ }^{87}$ See, e.g., Alcacer and Gittelman, supra note 70; Sampat, supra note 73; Paola Criscuolo and Bart Verspagen, Does It Matter Where Patent Citations Come From? Inventor versus Examiner Citations in European Patents, Research Memorandum 017, Maastricht: MERIT, Maastricht Economic Research Institute on Innovation and Technology (2005).

${ }^{88}$ See, e.g., Adelman and DeAngelis, supra note 17, for a critique of various statistical studies of patent citations.

${ }^{89}$ Id.
} 
making such assumptions and are tailored to highly heterogeneous systems, in which broad, skewed distributions are typical.

\section{III.B The Evolving Patent Citation Network: Is Patenting Getting Out of Hand?}

It is widely remarked that patenting has burgeoned since the 1980s and almost equally widely alleged that patenting is getting out of hand -- that patents are increasingly of low quality, providing the transaction costs of a divided and proprietary knowledge base without the benefit of spurred innovative progress. In fact, the number of patents issued by the USPTO has increased more or less exponentially since the patent system was inaugurated in 1790, and it is true that the rate of increase, which had been more or less constant since 1870, sharpened noticeably in the early 1980s. (See Figure 6.) In and of itself an increase in patenting is an ambiguous signal, however. The early 1980 s was a time of both technological ferment and changes in patent law. Both the computer revolution and the biotechnology industry got their starts at around this time. Moreover (and not coincidentally), the Supreme Court in 1980 and 1981 issued its opinions in Diamond v. Chakrabarty ${ }^{90}$ and Diamond v. Diehr, ${ }^{91}$ putting its stamp of approval on the patentability of biological materials and computer software, respectively. In 1983, the Federal Circuit Court of Appeals published its first patent opinion, ${ }^{92}$ inaugurating what many have argued has been an era of patent-friendly legal review after a period of purported judicial hostility to patentees. ${ }^{93}$

Any evaluation of the significance of the patenting boom must thus attempt to distinguish among potential causes, which encompass at least three possibilities.

${ }^{90} 447$ U.S. 303 (1980).

${ }^{91} 450$ U.S. 175 (1981).

${ }^{92}$ In re Hick, 699 F.2d 1331 (1983).

${ }^{93}$ See, e.g., Merges (2000), supra note 46. 
Increased patenting might stem from a faster pace of technological change; from a broader range of patented technology (which may have resulted both from the extension of the scope of legally patentable subject matter and from technological advances that have broken new ground); or from a weakened legal patentability standard. In this section we use a network approach to separate these effects. Our results indicate that not only the pace of innovation and breadth of patented technology, but also the pattern of patent citations has changed in recent years. The change in citation patterns indicates an increasingly skewed distribution of "citability" for patents issued beginning in the late 1980s. If "citability" reflects technical value, then the increasing gap between the most and least citable patents reflects an increasing gap between most and least valuable patents beginning in the late 1980s.

While a definitive interpretation of this change is not possible without further investigation, we argue that this change is not likely to be due entirely to an increased pace and scope of patentable innovations and that it suggests that patentability standards have been weakening. The timing of the increase in citability stratification is suggestive of an association with the Federal Circuit's increasing reliance on the "motivation or suggestion to combine" test for nonobviousness. It is also possible that increased citability stratification might stem from a perception of increased business strategic value of patents. An effectively lower "patentability" standard might reflect decreased barriers to applying for patents rather than weakened standards for issuing patents. The legal patentability standard places a lower limit on the extent to which businesses can simply "choose" to patent more trivial inventions, however. 
In this Section we describe the results of our study of the evolution of the pattern of citations in the patent citation network. In analyzing the patent citation network, we have used the Hall, Jaffe, and Trajtenberg dataset, ${ }^{94}$ which includes the approximately 16 million citations made by the more than two million patents issued by the USPTO between 1975 and 1999, as well as updated citation data from the USPTO that extends to $2006 .{ }^{95}$ We begin by discussing the effects of innovative pace and breadth on the network's evolution and explain why these effects are not sufficient to explain what is happening in the network. We then turn to the heart of our analysis, in which we demonstrate that since the late 1980s patents have become increasingly stratified in their citability. We interpret this increasing stratification as evidence of an increasing gap in technical value between the most and least valuable patents. We then argue that this increasing value gap is likely to be due to a lowering patentability threshold and that changes in the nonobviousness standard may have been responsible.

\section{III.B.1 Concerning the Pace and Breadth of Innovative Progress}

Before describing our analysis of the changing pattern of citations, which we argue suggests a lowering of the standard of patentability, we consider how to separate out the effects of either a faster pace of technological advance or a broader landscape of patented technologies. We certainly do not deny that the pace of technological progress may be increasing and that the breadth of patented technology has expanded. However, we do not aim to investigate those effects here. Rather, we want to find out whether additional important changes in patenting may be occurring.

\footnotetext{
${ }_{95}^{94}$ Hall et al, supra note 72.

${ }^{95}$ Our analysis includes all of the patents and citations in the database. We do not randomly sample the data.
} 
For this reason, in our analysis we measure time and patent age in units of patent numbers, rather than in units of months and years. We do this to mask out any effects of a mere "speed-up" of technological progress. If innovation is simply occurring at a faster pace without any change in the innovative "step" between patents or the character of the relationships between patents, then measuring "age" and "time" in terms of patent numbers should cancel out the effects of the increasing pace. After canceling out this source of time-dependence, remaining changes that we observe must be due to some more fundamental change in the way in which the citation network is evolving.

Accounting for the effects of a possible broadening of the subject matter of patented technology is a bit more difficult. To understand this issue, imagine a "landscape" of patented technology. As more patents are issued, they might overlap the existing "landscape" by claiming a somewhat improved or different version of a wellestablished technology -- such as coffee filters or disposable diapers, for example. Alternatively, they might strike out into new territory by, for example, being the first patent to claim a practical application of a scientific advance, such as stem cell research. While this is surely an over-simplified view of the complexities of technological advancement, it is perhaps sufficient to illustrate that there is a distinction between the size of the innovative step represented by a new patent (how much better is the claimed disposable diaper, for example) and the extent to which it represents a broadening of the technological landscape. This distinction should be reflected in the patent citation network, though how to decipher the relevant patterns in detail is a subject for future research. For present purposes, a few simple observations are sufficient. 
We have measured two quantities that are relevant to the question of to what degree the "space" of patented technologies is "spreading out" as opposed to "filling in." The first is the average number of citations made per patent. As shown in the top graph in Figure 7, the average number of citations made per patent has been steadily growing (in fact, nearly proportional to the number of patents, which is our measure of time) throughout the period of our data. This increase in citations made per patent is consistent with an increasingly dense space of narrow patents, with new patents having an increasing number of patents to cite because more and more patents are material. It is similarly consistent with patenting of smaller and smaller incremental advances, such that inventors need to cite more patents to reach back to all those which are relevant to the claims of the new patent. It would also be consistent with an increased issuance of patents that are based on combinations of older technology. But the increasing number of citations made per patent seems unlikely to have been caused by expansion of the technological frontier. Patents that are breaking new ground by heading off in uncharted technological directions would, if anything, seem likely to encounter fewer material prior art patents to cite.

Some criticisms of the recent evolution of the patent system, particularly those in the popular press, have highlighted another way in which the breadth of patented technologies might be expanding by providing examples of "outlier" patents (often of a somewhat humorous character) such as the much-discussed peanut-butter-and-jelly sandwich patents. ${ }^{96}$ If the landscape of patented technology were being expanded significantly by the addition of such "outlier" patents, one would expect that the average

96 See, e.g., Gary L. Reback, Patently Absurd: Too Many Patents are Just as Bad for Society as Too Few, Forbes, (Jun. 24, 2002); Varian, Hal R., Patent Protection Gone Awry, New York Times, Economic SCENE (October 21, 2004); see also http://www. patentlysilly.com. 
citability of brand new patents would decline since such patents would be less likely to spawn improvements and follow-on innovation than patents on more mainstream technology. In fact, our analysis of the citation network's evolution finds that the average likelihood that a new patent will be cited by the next patent that issues has increased somewhat in recent years due to the increasing number of citations made by each patent (see the bottom graph in Figure 7), suggesting that true technological "outlier" patents, while making for entertaining rhetoric, are not a major part of the patenting explosion.

On the whole then, as the number of patents has increased, patent examiners and applicants have deemed it necessary to cite more patents, suggesting that the density of "mainstream" patents is increasing despite the undeniable increase in the breadth of patented technology.

Having accounted for a possible speed-up in innovative progress through our choice to measure time and age in units of patent numbers and having concluded that recent citation patterns are not likely to be explained solely in terms of an expansion of the breadth of patented technology, we now turn to the question of whether something else is going on in the patent system beyond an overall "speeding up" or "spreading out."

\section{III.B.2 The Evolving Citability Distribution}

Our approach is motivated by statistical physics studies of a diverse range of other growing networks. We describe the evolution of the patent citation network in terms of the probability that a patent with given characteristics will be cited, which we call "citability." To get a result that will provide insight into the general features of the network evolution, we attempt to describe the probability of citation using only those characteristics that strongly affect the likelihood that a given patent will be cited. 
Because a case-by-case evaluation of the underlying reasons that one patent might cite another is impossible for a large network of citations, we look for objective characteristics that we expect, on average, to be good proxies for the underlying citation process. In our study, we hypothesize that we will be able to describe the evolution of the patent network to a very good approximation by assuming that the probability that a particular patent will be cited at a given time depends primarily on its age, which we will call 1 , and on the number of times it has already been cited, which we will call k. ${ }^{97}$ Our results bear out the hypothesis that, on average, these two characteristics are highly determinative of the likelihood that a patent will be cited.

Our assumption that the probability that a patent will be cited depends on its age requires little explanation -- technology tends to become obsolete. Our expectation that the probability that a patent will be cited depends on how many citations it has already received derives both from our intuitions about patents and from experience with other evolving networks. As we discussed in Part II, one of the most interesting discoveries of network science has been that it is very common for nodes that already have many links to acquire additional links more quickly than nodes with fewer links. This preferential attachment or, colloquially, "rich get richer" phenomenon might also be reasonably expected to occur in the patent citation network.

There is considerable statistical evidence that highly cited patents are more valuable and may be of greater technological merit. Moreover, technology has its own "popular crowd," depending on what field is "hot" at a particular time. In our analysis,

\footnotetext{
${ }^{97}$ A more complete description of our data analysis procedure is available in our technical publication, Gábor Csárdi, Katherine Strandburg, László Zalányi, Jan Tobochnik, and Péter Érdi, Modeling Innovation by a Kinetic Description of the Patent Citation System, forthcoming in PHYSICA A (2006). available at http://www.arxiv.org/abs/physics/0508132.
} 
we make no assumptions about exactly how and for what reason a patent's chances of being cited might depend on how many citations it has already received. We simply "guess" that the number of previous citations to a patent, which we call $\mathrm{k}$, will be relevant to its likelihood of being cited again. Our computations confirm that guess, as we will explain below.

Of course, the fact that we extract a citation "probability" is not meant to suggest that the particular citation choices made by patent examiners or applicants are actually random. Our results mean only that, cumulatively, those individual citation decisions result in a likelihood of citation which depends in interesting ways on $\mathrm{k}$ and $1 .^{98}$ Patents presumably have inherent "quality" that affects whether they are cited, just as individuals have personalities that make them more popular and websites have content that make them more useful. Our present analysis says nothing directly about the inherent patent quality of any particular patent, but does allow us to make reasonable inferences about the patent system as a whole based on the observed citation distribution and the way in which it has changed in recent years.

To find the likelihood of citation for given $\mathrm{k}$ and $\mathrm{l}$ we developed a novel iterative technique which we used to extract, from the patent citation data, the average likelihood that a patent with $\mathrm{k}$ previous citations of age 1 will be cited again. We do not assume a particular functional form for this probability -- the functional dependence on citations previously received and patent age is derived directly from the data. For present

\footnotetext{
${ }^{98}$ There is also an overall time-dependent scale factor, $\mathrm{S}(\mathrm{t})$ (where $\mathrm{t}$ is measured by patent numbers). More specifically, we find that the probability function $\mathrm{P}(1, \mathrm{k}, \mathrm{t})$ can be written to a good first approximation as the ratio of a time-independent function, $\mathrm{A}(\mathrm{k}, \mathrm{l})$, and a time-dependent scale factor, $\mathrm{S}(\mathrm{t})$. The scale factor $\mathrm{S}(\mathrm{t})$ is just the sum of $A(k, l)$ over all existing patents at time $t$. Thus $S(t)$ changes over time only because the number of patents of age 1 and connectedness k changes. See our technical paper, available at http://www.arxiv.org/abs/physics/0508132, for a detailed explanation of this factor.
} 
purposes, let us focus on the way in which the probability of being cited depends on $\mathrm{k}$-the number of citations already received. We will return to the dependence on age in Part IV.

As it turns out, the way in which the probability of being cited depends on $\mathrm{k}$ is more or less the same for patents of any age. (See Figure 8.) The likelihood that a patent will be cited does depend on its age -- very young patents are not cited much, then the likelihood of being cited grows rapidly in the first couple of years after a patent issues, and then it falls slowly thereafter. (See Figure 9.) But no matter the age of the patent, the ratio of the likelihood that a patent with ten previous citations will be cited to the likelihood that one with three previous citations will be cited is nearly the same. So if, for example, patents that are 10,000 patent numbers "old" are five times more likely to be cited if they have ten previous citations than if they have three, roughly the same will be true for patents that are 100,000 patent numbers "old."

The way in which the likelihood of being cited depends on the number of citations already received, which we call $\mathrm{A}_{\mathrm{k}}(\mathrm{k})$, is shown in Figure 8, which displays the results extracted from the data for patents of several different ages. The more often a patent has already been cited (the higher its value of $\mathrm{k}$ ) the more likely it is to be cited again (the higher its value of $\left.A_{k}(k)\right)$-- the signature of preferential attachment.

This demonstration of "preferential attachment" in the patent citation network is not especially surprising -- preferential attachment is a common property of growing networks and is intuitively sensible in the patent system. Preferential attachment is cumulative -- highly cited patents are more likely to be cited, hence becoming even more

\footnotetext{
${ }^{99}$ Mathematically, this means that the likelihood of being cited can be written approximately as a product of two functions, i.e., $A(k, 1)=A_{l}(1) A_{k}(k)$. $A_{l}(1)$ depends only on age while $A_{k}(k)$ depends only on the number of citations previously received.
} 
highly cited and even more likely to be cited, and so forth. The pattern of "citability" shown in Figure 8 thus eventually leads to an extremely skewed distribution of citations eventually received by patents. (See Figure 1, which shows the proportion of patents that had received $0,1,2, \ldots$ citations.) Most patents are hardly cited at all, while a few patents become citation "billionaires" (well, "hundredaires," really). If we make the reasonable (and empirically supported) assumption that the number of times a patent is cited signals its technological value, ${ }^{100}$ we can infer that the very skewed and broad citation distribution in Figure 1 reflects a very stratified distribution of patent values, with a few superstars and a vastly larger number of patents that go nowhere.

This general picture of a highly skewed patent value is well known by now. ${ }^{101}$ Our network analysis allows us to get behind this general observation, however, to ask just how stratified patent value is and how the extent of stratification has evolved over time. If more patents are being issued simply as a result of faster or broader technological progress, we would expect the degree of stratification to remain about the same over time. There would be proportionally more superstars as well as proportionally more "duds," but the extent to which the superstars predominated over the duds would be more or less unchanged. On the other hand, if the patentability standard is lowered, there would be not only more patents issued, but a higher proportion of them would be less important -- the degree to which highly citable patents dominate trivial patents should increase.

\footnotetext{
${ }^{100}$ See, e.g., Lemley et al, supra note 13 at 449 and citations therein.

${ }^{101}$ See, e.g. Bessen and Meurer, supra note 47 at 8; F.M. Scherer \& Dietmar Harhoff, Technology Policy for a World of Skew-Distributed Outcomes, 29 RES. POL'Y 559 (2000).
} 
The citability function, $A_{k}(k)$, gives us a quantitative handle on the degree of stratification among issued patents. We arrive at this function after factoring out the effects of patent aging due to obsolescence (which, as noted, turn out to be roughly the same no matter how may citations a patent has previously received) and it thus gives a relatively simple and unobscured view of the underlying "citability" of patents. Looking at Figure 8 we see that the citability of a patent on average increases somewhat more than proportionally to the number of citations already received. We can quantify this "somewhat more" by noting that $A_{k}(k)$ is closely fit by the form $A_{k}(k) \sim k^{\alpha}$. The parameter $\alpha$ is a measure of the extent to which highly cited patents are preferred. When averaged over all of the data from 1975 on, $\alpha \cong 1.19$ (with an estimated error of less than $.01)$

To give us a feel for the interpretation of the values of $\alpha$, we can compare this value for the patent system to known results from other network studies. If there were no aging or obsolescence, nothing would inhibit old patents from acquiring extremely large numbers of citations. In that situation, theoretical network models have shown that when $\alpha$ is larger than 1 the network "condenses" to a highly unequal situation in which nearly all nodes in the system have very low connectivity. These "unimportant" nodes are all connected to a very small (finite even in an infinite network) number of very highly connected nodes ${ }^{102}$-- almost all nodes are "peons" connected to a very few "royal" nodes and there is no "middle class" of moderately connected nodes. In the patent system, such an extreme stratification does not occur because highly cited patents eventually become

${ }^{102}$ P.L. Krapivsky., S. Redner, and F. Leyvraz, Connectivity of Growing Random Networks, 85 PHYS. REV. LETT. 4629-32 (2000). 
obsolete and generally cease to be cited. However, the fact that $\alpha>1$ in the patent network still suggests that citations are highly concentrated -- there is a highly unequal distribution of patent "citability."

What is most interesting for present purposes is that the network analysis gives a means to investigate the way in which the degree of stratification in patent citability has varied over time. We do this by calculating $\alpha$ using only the patents within a 500,000patent sliding time window and calculating a value for $\alpha$ after every 100,000 patents. The value of $\alpha$-- and hence the degree of stratification of patent citability -- has varied in an interesting way since 1982 (the earliest date for which we can make the calculation) as can be seen in Figure 10. While Figure 6 shows that the number of patents issued annually has been rising essentially since the inauguration of the patent system and rising very rapidly since the early 1980 s, the stratification of citability, as reflected in the value of $\alpha$, decreased slightly after 1982. (We do not know what was happening to it earlier because we do not have sufficient earlier data). Beginning in the late 1980s, however, it began to rise and continued to rise throughout the period of our analysis. Thus, during a period throughout which the absolute number of patents issued was rapidly rising, the relationships between those patents were also changing -- but not in a way that simply reflects increasing numbers. Patent citability became increasingly stratified. The increase in $\alpha$-- corresponding to increasingly stratified citation patterns -- began nearly 10 years later than the beginning of the recent rise in patent issuance a few years after the major change in the patent system represented by the inauguration of the Federal Circuit Court of Appeals.

\section{III.B.3 Interpreting the Increasing Stratification of Patent Citation Patterns}


How should we interpret the increasing stratification of patent "citability" since the late 1980s? One plausible interpretation, and the one that we find most convincing in light of our investigation of the patent citation network thus far, is that the patentability standard has decreased, resulting in the issuance of a larger fraction of more trivial -- and hence less citable -- patents. The timing suggests that the increasing stratification is unlikely to have resulted from the opening up of the patent system to patents on biotechnology (which happened around 1980), software (again around 1980), or business methods (the State Street Bank opinion issued in 1998). ${ }^{103}$ We suggest that one legal change which may have resulted in the observed increasing stratification of patent citability (and, by inference, technical value) was a decreasing standard of nonobviousness adopted by the Federal Circuit Court of Appeals (followed of course by the USPTO and, presumably, by patent applicants themselves in making their filing decisions), reflected in the "teaching, suggestion, or motivation to combine" test for nonobviousness, which was used increasingly by the Federal Circuit. (Figure 11 shows the increasing use of the "suggestion test" by the Federal Circuit.)

While we believe that a weakening patentability standard is the most likely explanation for the increasing stratification of patent citability -- and, inferentially, the increased disparity in patents' technical worth -- there are other possible explanations. Perhaps the increasing stratification is due, not to an increasing issuance of trivial patents, but to an increasing issuance of more highly citable pioneer patents. Another possibility, which we plan to explore in future studies, is that the average stratification parameter $\alpha$ is

${ }^{103}$ State Street Bank and Trust Co. v. Signature Financial Group, Inc., 149 F.3d 1368 (Fed. Cir. 1998). It is also possible that the degree of stratification of citations depends on the particular technological area. Perhaps, for example, preferential attachment is more pronounced in fields that depend on pioneering research advances. If this is the case, an overall increase in patenting in a more "stratified" filed could lead to increasing overall stratification. 
changing because of changes in the subject matter "mix" of patented technologies. If patent "importance" is inherently more stratified in one field of technology than in another (because of a difference in the importance of "pioneer" patents, for example), then an increasing prevalence of patents in that field could change the average degree of stratification that we observe. Preliminary studies of a rough division of patents into six technological categories did not turn up any significant variations in $\alpha$, but a more indepth study of differences between technological fields is under way. This possibility is especially interesting because the timing of the increased stratification in the late $1980 \mathrm{~s}$ corresponds to the time at which the Internet began to take on central social significance. Another possibility is that the change in citability over the years reflects a change in citation practice, rather than a change in inherent patent characteristics. We are inclined to reject this possibility at present because most of the trends in patent citation practice that we can think of -- most notably the increased ease of computerized searching for prior art -- seem unlikely to have changed direction from decreasing $\alpha$ to increasing $\alpha$ in the 1980 s. Computerized searching seems likely to have had a "one-way" influence. One way to check for the influence of search technology would be to compare the behavior of the United States patent citation network with other citation networks, such as the European patent citation network or the network of citations in scientific journals.

To summarize, in this Part we have shown empirically that the distribution of patent "citability" has been changing in recent years. Prior to the late 1980s, "citability" was becoming slightly more "egalitarian" -- the difference between the citability of the most highly cited patents and that of less cited patents was decreasing. From the late 
1980s on, that trend has been reversed. 'Citability' has become more stratified, with highly cited patents becoming more and more citable compared to less cited patents. In line with our intuition and with earlier studies of patent value, we interpret citability as a reflection (on average) of technological importance. We thus conclude that the distribution of patent importance has also become more stratified since the late 1980s. Though there are other possible explanations of this trend, we hypothesize that it may result from a lowered patentability threshold possibly reflected in the "teaching, suggestion, or motivation to combine" test of non-obviousness, and resulting in the issuance of more trivial patents.

\section{Of Sleeper Patents and Innovative Progress: How Innovation Builds on Prior Technology}

To render the analysis tractable, most studies of the process of innovation reflected in the legal and economic literature have taken a simplified, linear view in which innovation is pictured as "sequential" or "cumulative," each new advance building on a previous innovative step. In fact, of course, innovation is a much more complicated process involving new advances, combinations of old technologies, and potentially reaching back into the past to make new uses of technologies that acquire new relevance in light of some new advance. "Percolation" and recombination models of innovation attempt to incorporate the non-sequential character of innovation. ${ }^{104}$

A network approach permits us to take into account the multi-dimensional and combinatorical nature of technological progress. Social scientists have taken steps in this direction. They have studied the process of innovation by viewing patents as "footprints"

\footnotetext{
${ }^{104}$ See, e.g., Fleming, supra note 73; Fleming and Sorenson, supra note73; Gerald Silverberg and Bart Verspagen, A Percolation Model of Innovation in Complex Technology Spaces, 29 J. ECON. DYNAMICS AND CONTROL 225 (2005).
} 
of technological change. ${ }^{105}$ From this perspective, citations may be viewed as indicators of the ways in which prior technologies have been combined to produce a new invention. These studies have implications for patent law and policy because a well-designed patent system should reflect the way in which technological progress actually occurs. ${ }^{106}$

In this vein, Fleming and Sorenson and their collaborators ${ }^{107}$ used patent citations in combination with the USPTO classification system to explore the way in which innovation proceeds as a process of search and recombination of prior technologies and to argue that successful innovation is a balance between re-using familiar components -an approach that is more certain to succeed -- and combining elements that have rarely been used together -- an approach that is more likely to fail entirely, but also more likely to result in radical improvements.

Podolny and Stuart and collaborators also made explicit use of social network analysis by using a basic network measure of local network structure, the "transitivity," to study the innovative process. ${ }^{108}$ Transitivity measures the likelihood that two nodes that are connected to a specific third node are also connected to one another. Figure 12 illustrates this concept. In the patent context, transitivity measures the likelihood that two patents that cite or are cited by the same patent also cite one another.

The network concept of "transitivity" is related to the suggestion in econometric studies of patent citations that patent importance should be related to a patent's

\footnotetext{
105 See, e.g., Fleming, supra note 73; Fleming and Sorenson, supra note 73; Joel M. Podolny, Toby E. Stuart, and Michael T. Hannan, Networks, Knowledge, and Niches: Competition in the Worldwide Semiconductor Industry, 1984-1991, 102 AMER. J. SociologY 659 (1996); Joel M. Podolny and Toby E. Stuart, A Role-Based Ecology of Technological Change, 100 AMER. J. SOCIOLOGY 1224 (1995).

${ }^{106}$ Though those studies are subject to the caveat that they have thus far not taken into account the possibility that the quantum of innovation signified by a patent can change as a result of legal doctrine.

${ }^{107}$ Fleming, supra note 73; Fleming and Sorenson, supra note 73.

${ }^{108}$ See Podolny, Stuart, and Hannan, supra note 105; Podolny and Stuart, supra note 105.
} 
"generality," which is defined in terms of the variety of USPTO classifications of the patents that cite it, and "originality," which is defined in terms of the variety of USPTO classifications of the patents that it cites. ${ }^{109}$

Podolny and collaborators used transitivity-type quantities to define local measures of "competitive intensity" and "competitive crowding" based on indirect patent ties. ${ }^{110}$ A basic insight of their work is that if many innovations are building on the same technological antecedents and, thus contributing very similar technological outputs, the likelihood of a new entrant into the associated niche is lowered. They used network transitivity measures to observe how a technological "niche" can become popular, but then overly crowded and "exhausted" as a result of a flurry of inventive activity in the niche. They point out that counting the numbers of citations made or received is not sufficient to identify "crowded" niches -- an innovation that provides a technological foundation for a variety of unrelated advances will be highly cited without crowding. Indeed, as we have shown here in Part III, in the patent citation network the likelihood of further citation increases the more popular a patent becomes. Podolny et al. provide an interesting way to distinguish between highly cited patents. Their work suggests that a patent that has been cited by a large number of patents which also cite one another (high transitivity) is less likely to be cited again than a patent that has been cited by a large number of patents which are not linked to one another. Transitivity measures thus show promise as means to distinguish patents in "hot" fields from "important" patents.

\footnotetext{
${ }^{109}$ See, e.g., Hall, Jaffe, and Trajtenberg, supra note 72. Variations on transitivity provide potential alternative measures of "generality" and "originality" that should be less dependent on the ad hoc USPTO classification scheme. (See Figure 12.)

${ }^{110}$ See Podolny, Stuart, and Hannan, supra note 105; Podolny and Stuart, supra note 105.
} 
Our study of how patent citability depends on patent age adds to this line of research. In Part III, we focused on the way in which patent citability depends on the number of times a patent has been previously cited. In the course of our analysis, we also determined how patent citability depends on a patent's age (in patent numbers). Just as we learned that the way in which a patent's citability varies with the number of citations it has already received is roughly the same for patents of all ages, we also found that the way in which patent age affects the likelihood of being cited is nearly the same no matter how many times a patent has been cited before. Thus, the dependence of citability on age, which we call $\mathrm{A}_{1}(1)$, is relatively independent of $\mathrm{k}$, especially at large 1 and $\mathrm{k}$, as shown in Figure 9 for several values of $\mathrm{k}$.

Not surprisingly, citability peaks at a relatively young age (small 1), More interestingly, citability decays unexpectedly slowly for older patents. ${ }^{111}$ For large $1, A_{1}(1)$ $\sim 1^{-\beta}$, where $\beta \cong 1.6$. This power law form signifies a long, slow decay -- very old patents are still being cited. This observed dependence of citation probability on patent age provides insight into the complicated dynamics of technical innovation. The peak in citations relatively soon after issuance likely corresponds to "typical," incremental improvements, such as those reflected in linear models of cumulative innovation. Such incremental advances are likely to occur relatively soon after a patent issues. The tail of citations that occur long after issuance no doubt includes "pioneer"-type patents that continue to influence innovation (and hence to be cited) over long periods of time. However, not all of these late citations are to broad, pioneer patents. The form of $A_{l}(1)$-including the tail of citability long after issuance -- is the same even for patents that have

${ }^{111}$ Previous studies of citation lags have also noted that old patents continue to be cited. See, e.g., Hall et al., supra note 72 at $421-24,448-41$. 
rarely been cited in the past. This means that even patents that have been cited very rarely or never in the past are sometimes cited long after issuance.

Thus there is no age at which patents can be pronounced "dead." While most patents that have not been cited shortly after they are issued will never be cited, there are "sleeper" patents that go without citation for long periods of time, only to reawaken at a later time. If one makes the reasonable assumption that receiving a citation is some indication of social value, this observation suggests that inventive progress is not simply a matter of steady accumulation of incremental progress, but a complicated process in which old patents may gain new significance in light of later advances. The long tail of inventive relevance also underscores the difficulty of predicting the social value of innovations in advance.

Studying network metrics and their evolution over time moves the study of innovation using patent data beyond a focus on average number of citations made and received to delve into the way in which inventions are combined, recombined, and reused to produce new innovations. In the future, we can build on our work and the social science studies discussed above by combining the approaches. For example, we might investigate the extent to which delayed citations in the power law tail of the $A_{1}(l)$ function target patents with high "originality" (low transitivity) which connect disparate technologies.

\section{Future Directions and Some Preliminary Results}

The network approach has the potential to elucidate other questions of patent and innovation policy, some of which we discuss briefly here.

\section{IV.A. Patent Classification and the Meaning of Analogous Arts}


The categorization of patents by technological field of endeavor is of both practical and analytical significance. Patent classification plays an important role in prior art searching. Moreover, under the patent doctrine of "analogous arts," the technological field of endeavor determines which prior art patents must be considered in determining whether a claimed invention is nonobvious. ${ }^{112}$ Though the law requires that novelty be absolute, nonobviousness is judged only with respect to prior technology in "analogous arts" of which a "person having ordinary skill in the art" would reasonably be apprised. To apply this standard, it is necessary, of course to determine which fields of technology are "analogous" to the field of the patented invention and which patents are in a relevant "art." Moreover, any study of technological innovation or of the functioning of the patent system which relies on patent data and seeks to inquire into potential differences between fields of technology must find some means of categorizing patents.

At present, each patent application is categorized by a USPTO examiner according to a scheme of classes and subclasses that has been developed in an ad hoc manner over the years. The classification is used to assist examiners and patent applicants in searching for relevant prior art. The USPTO patent classifications have also been used by researchers to assess such things as the "generality" of a patent (evaluated by the extent to which it is cited by patents from different classes), the "originality" of a patent (evaluated by the extent to which it cites patents from different classes), the "technological closeness" of firms involved in patent litigation (evaluated by the extent to which the patents assigned to those firms are in the same classes), and the way in which

\footnotetext{
${ }^{112}$ ChISUM ON PATENTS $§ 1504.03$; MPEP $\S 904.01(\mathrm{c})$.
} 
innovations recombine components from the prior art. ${ }^{113}$ The usefulness of these measures is limited, however, by the fact that the classification scheme is ad hoc and does not provide a well-defined way to measure the degree of distinctiveness between inventions in different subclasses or classes. A more objective and quantitative measure of patent "closeness" is desirable.

Network analysis provides an alternative way to measure technological distance that is more fine-grained and quantitative than comparing USPTO classifications and less ad hoc than the classifications themselves. The number of citation "hops" that it takes to get from one patent to another is one way of measuring how "far apart" two patented technologies are. Essentially, patented technology is likely to be related most closely to the technology of the patents it cites or is cited by directly, less closely to the technology of the patent that is two steps away, and so on. The citation path length measure may be used both to evaluate the existing classification scheme and as an alternative to measures based on it.

In a preliminary study, we have measured the overall "size" of the patent citation network by looking at the shortest path lengths between patent nodes. As discussed in Part II, one of the most interesting results of network science studies is that many networks have what has come to be called the "small world" property. ${ }^{114}$ This property, made famous by the phrase "six degrees of separation"115 and by the "Kevin Bacon

\footnotetext{
113 James E. Bessen and Michael J. Meurer, The Patent Litigation Explosion, Boston Univ. School of Law Working Paper No. 05-18, available at http://ssrn.com/abstract=831685 (2005); Fleming, supra note 73; Fleming and Sorenson, supra note 73; Jaffe and Trajtenberg, supra note 73.

${ }^{114}$ See WATTS, supra note 2; Newman supra note 2; Albert and Barabasi, supra note 2; Watts and Strogatz, supra note 25 for discussions of the basic properties of small world networks.

${ }^{115}$ See WaTtS, supra note 2; S. Milgram, The Small World Problem, 2 Psychology Today 60-67 (1967) (reporting Milgram's famous experiment which involved counting the number of transfers necessary to get
} 
game," the small world property, one counts how many "hops" from node to node along the network must be made to travel between any two nodes. The number of hops along the shortest path between two nodes is sometimes called the "geodesic distance." The maximum geodesic distance between any two nodes in the network is the "diameter" of the network. If the maximum geodesic distance between any two nodes in a network remains relatively small, ${ }^{117}$ the network has the "small world property." The diameter of many real world networks is surprisingly small. ${ }^{118}$

We have determined so far that the patent citation network displays the small world property discussed in Part II.A.1.b. The longest directed path length between nodes in a "giant" component (of nearly 4 million patents) is only 24 steps, ${ }^{119}$ while the average is 6.9 steps. An approximate calculation on the undirected patent citation network has been performed by Leskovec et al. ${ }^{120}$ They determined, using a sampling method, that the average undirected path length is about 10 steps. They also determined that the "size" of the patent citation network has been shrinking over time, even though the number of patents has increased dramatically. This shrinking diameter may indicate increasing interdisciplinarity (interdisciplinary patents will cite patents in disparate fields, thus providing a network "shortcut" between disciplines) or the increasing importance of

a letter delivered from an arbitrary individual in Omaha, Nebraska to a specified individual in Sharon, Massachusetts).

${ }^{116}$ The Kevin Bacon Game, which may be played at http://www.cs.virginia.edu/oracle/, counts any two actors as linked if they have had roles in the same movie. The "Oracle of Kevin Bacon" shows that any two of the 800,000 or so actors in the Internet Movie Database are linked to Kevin Bacon in an average of fewer than 3 steps.

${ }^{117}$ Technically, if it increases no more rapidly than the logarithm of the number of nodes.

${ }_{118}$ See, e.g., WATTS, supra note 2, Newman, supra note 2, BARABASI, supra note 2.

${ }^{119}$ The giant component contains more than two million patents because it includes cited patents from before 1975 .

${ }^{120}$ Jure Leskovec, Jon Kleinberg, and Christos Faloutsos Graphs over Time: Densification Laws, Shrinking Diameters and Possible Explanations, KDD’05, ACM (2005). 
"bridge" technologies which are used in a number of fields. We plan to study the distribution of directed and undirected path lengths in more detail and, if the shrinking "size" is confirmed, will combine path length measures with the USPTO classification scheme to understand the source of the closer connectedness of the network.

Besides giving us an overall view of how closely connected the patent space is, the network path length may also be used to evaluate and explore existing patent classification schemes. Distances between patents in the same USPTO category may be compared with distances between patents in different categories to evaluate the accuracy of the classification system. Moreover, average distances between different categories can be computed. Path length measures may provide a more fine-grained (and complementary) measure of technological closeness than metrics that use the number of overlapping subclasses in the USPTO classification system.

The small world property of the network also suggests the intriguing possibility that a relatively small number of "hub" or "bridge" patents are integral to many apparently separate fields (and thus provide "shortcuts" between patents in disparate fields). In future work, we hope to investigate that possibility and to study qualitatively any "hub" or "bridge" patents that we can identify.

\section{IV.B. Patent Thickets and Potential Anti-Competitive Licensing Practices}

The proliferation of patents results in a situation in which many commercial products require the use of more than one -- and in some cases hundreds of -- patented technologies. This situation raises a number of sometimes conflicting concerns. On the one hand, there is the fear of a patent "thicket" in which the transaction costs associated with obtaining the necessary patent licenses to do something of practical usefulness 
become so high as to undermine the social value of the patents. ${ }^{121}$ There can even be a hold-up problem in which the owners of contributing technologies cannot come to an agreement at all, as a result of differing assessments of the relative value of various contributions to a commercial product. ${ }^{122}$ There are two distinct ways in which such a transaction costs nightmare could arise. It might be that a commercial application requires many distinct and complementary patented technologies. This could happen either as a result of increasing complexity in the technology itself or as a result of patenting more and "smaller" pieces of technology space. A need for many patent licenses might also be due to "patent blocking." Patent blocking occurs when a patent improves on the invention claimed in another patent in such a way that the claims of the earlier patent still cover the improved invention. Where patent blocking occurs, licenses to a string of "nested" improvement patents may be required to use one particular technology. In either case, one way to handle the necessary cross-licensing and cut down on transaction costs is for the owners of the relevant patents (who are often commercial entities in the same industry) to form "patent pools.",123

A high density of patents in a particular technological "niche" need not always indicate a patent thicket, however. Closely related patented technologies may be potential substitutes for one another -- creating something more like patent supermarkets offering many nearly interchangeable options than patent thickets. If these patents are separately owned, competition between patent holders will reduce licensing fees and the issue of hold-up will not arise. In situations like this, in contrast to the patent thicket situation, patent pools and cross-licensing agreements between industry actors may be

${ }^{121}$ See, e.g., Shapiro, supra note 46; Bessen, supra note 59.

${ }^{122}$ See, e.g., Merges, supra note 60.

${ }^{123}$ See, e.g., Shapiro, supra note 46; ; Goller, supra note 61. 
anti-competitive. Rather than serving to reduce transaction costs and avoid hold-up, such agreements may permit firms to avoid competing for licensing revenues and drive up royalties.

Distinguishing between these two kinds of relationships between patents is of great theoretical and practical interest. Citation network structural measures may be useful in addressing questions related to the patent thicket issue. Prof. Gavin Clarkson has suggested that a high density of citations (meaning the fraction of possible citations that are actually made) in a particular patent neighborhood may suggest where patent pools might legitimately be formed. Setting aside some technical issues about how to compare citation densities from different sized network samples, citation density is a useful way to assess the level of technological interrelatedness in a particular field. ${ }^{124}$ Density alone cannot distinguish between patent thickets and patent supermarkets, in which closely related technologies compete for licensing "customers," however. The mere existence of a citation from one patent to another cannot tell us which scenario is most likely. Determining the meaning of a particular citation is an extremely laborintensive process requiring understanding of the legal and technical relationship between the citing and cited patents. To investigate the existence of patent thickets and the potential for related antitrust problems, some structural metric that is sensitive to the character of a citation is highly desirable. It may be possible to design such a metric based on transitivity concepts.

Podolny and Stuart note that a technological tie (and hence a likelihood of a citation) exists between two patents if "the contribution of [the second] incorporates,

${ }^{124}$ Clarkson, supra note 6. 
builds on, or is bounded by a technological contribution of [the first.]"125 The distinction between these relationship types is critical to understanding the extent to which increased patenting in a particular area signifies patent blocking and high-transaction-cost thickets or desirable designing around and competition.

As we alluded to above, patents may cite an earlier patent because they build on its technology (what one commentator has termed "lovely" citations) or because they replace or distinguish its technology ("dangerous" citations). ${ }^{126}$ Depending on the scope of a patent's claims, a "lovely" citation may mean that use of the later technology must be authorized by the owners of both patents. A "dangerous" citation, on the other hand, may mean that a prospective user of the related technologies can play them off against one another in bargaining for a license. The existence of "lovely" and "dangerous" citations is thus related to the potential for patent thickets and for antitrust problems when industry competitors sign cross-licenses or form "patent pools."

We suggest that a patent $\mathrm{C}$ that cites a patent $\mathrm{B}$ which makes a "lovely" citation to an earlier patent A is relatively likely to cite the earlier patent as well. (See Figure 12c.) This is because for a "lovely" citation, the claims of A are likely to be broader in scope than the claims of $\mathrm{B}$, and patent $\mathrm{C}$ must therefore be distinguished from both $\mathrm{A}$ and $\mathrm{B}$ to be patentable. If the citation is "dangerous," on the other hand, patent $\mathrm{C}$ may not need to be distinguished from patent A. Thus, on average, we would expect a group of patents in a high-transaction cost "thicket" to have a higher value of the variant of transitivity illustrated in Fig. 12c. We plan to investigate whether the Fig. 12c transitivity will provide insight into the extent to which patents in a given technical field tend to be

\footnotetext{
${ }^{125}$ Podolny and Stuart, supra note 105.

${ }^{126}$ Maurseth, supra note 73.
} 
competing substitutes or "blocking patent" complements. If we are successful in identifying a structural measure of this kind, it may be both of analytical use in understanding the prevalence of blocking patents in particular technical fields and of practical use in evaluating the potential anti-competitive effects of patent pools and crosslicensing agreements.

\section{CONCLUSIONS}

This Article began by arguing that network science is poised to begin making important contributions to legal scholarship by offering relevant concepts, empirical methods, and modeling techniques that will be better able than current approaches to account for the importance of heterogeneity and local network structure in determining collective behavior. Because networks are ubiquitous in the social problems to which the law is addressed, network science, we argued, may make a significant contribution to legal analysis. Network science is particularly promising for dealing with situations in which local relationships are important and heterogeneous. It provides means to illuminate the complicated relationship between local relationship patterns and structure and interactions and global, collective behavior.

In the second half of this Article, we illustrated how the network approach can be applied to study the patent citation network. In Part III we showed empirically that, not only has the number of patents been increasing rapidly in recent years, but citation patterns have been changing as well. The average "citability" of a patent increases very rapidly with the number of times it has already been cited, demonstrating the "preferential attachment," or "rich get richer," phenomenon observed in many complex

networks. Moreover, the extent to which highly cited patents are more "citable" than less 
cited patents has changed over time. Citability has become more stratified since the late 1980s. Since citability is likely related to a patent's technical importance, the increasing stratification suggests that the patentability standard may have decreased, resulting in the issuance of a larger fraction of more trivial patents. Neither a general increase in the pace of technological progress, nor a general broadening of patented technology seems to explain the increasing stratification of patent citability. In fact, the average number of citations made by a patent has increased over time, suggesting that patents inhabit a more and more densely crowded technological space on average.

The increasing stratification began in the late 1980s, a period which has no obvious connection with legal changes related to biotechnology, software, or business methods patenting, but is around the time that the "suggestion or motivation to combine" test for determining whether a claimed invention is obvious became increasingly established as the definitive Federal Circuit approach. ${ }^{127}$ One possible hypothesis, based on our study so far, is that a weakening of the non-obviousness requirement, perhaps associated with the "suggestion test," has given rise to a proliferation of patents on minor improvements over the prior art which typically have little impact on the development of the technology and are thus cited only for a brief period after issuance. We cannot rule out other explanations for the change in the pattern of citation network evolution, however.

\footnotetext{
${ }^{127}$ See, e.g., ACS Hospital Systems, Inc. v. Montefiore Hospital, 732 F.2d 1572, 1577 (Fed. Cir. 1984) ("suggestion or incentive"); In re Geiger, 815 F.2d 686, 688 (Fed. Cir. 1987) ("teaching, suggestion or incentive"); In re Oetiker, 977 F.2d 1443, 1447 (Fed. Cir. 1992) ("reason, suggestion, or motivation"); and In re Raynes, 7 F.3d 1037, 1039 (Fed. Cir. 1993) ("teaching, suggestion or motivation"). While the "suggestion test" was first applied by the Federal Circuit around 1983, when it began issuing opinions, the number of cases in which it was applied increased dramatically during the 1990s. An informal survey of Federal Circuit case law finds more than three times as many cases citing the suggestion test in 2000 as in 1990. (See Figure 11.)
} 
In Part IV we discussed how network-based analysis provides insights into the innovative process. For example, consistent with earlier statistical studies of citation lags, we found that the probability that a patent will be cited peaks at a relatively "young" patent age. But the citation probability also has a long, slow power law decay at older ages, suggesting that some patents retain their influence over very long times. ${ }^{128}$ Surprisingly, this persistent vitality of some older patents is seen even for patents which have received few or no citations -- thus even "unpopular" patents have a significant probability of being revived after a long period of dormancy. This complicated dependence on patent age is evidence of the highly nonlinear nature of innovation and suggests that there may be two different innovation "types" -- incremental innovation, for which the standard models of patents as incentives to investment may be relevant, and unpredictable innovation, which may be less susceptible to a simple incentive theory and more in line with "percolation" models of invention, in which incremental progress is coupled with complicated linkages back to previous technology. ${ }^{129}$ Social scientists have begun to apply social-network-based approaches, looking at local network structure, to validate theories of innovation based on concepts of search and recombination. It should be possible to incorporate and build upon these studies in the analysis of innovation policy from a legal perspective.

In Part V we reported some preliminary results of other network-based approaches to understanding the patent system. We suggested that the concept of network path length or "distance" may be a fruitful means to explore the connections

\footnotetext{
${ }^{128}$ This long tail in the probability of citation as a function of patent age is masked to some extent by the rapidly increasing number of younger patents in earlier studies which simply compute average distributions of citation lags. Our dynamic analysis disentangles these two effects.

129 Silverberg, supra note 109.
} 
between different technical "fields." A network measure of "technological distance" could be used to evaluate the USPTO classification scheme and as an alternative and more quantitative way to classify patents and to evaluate concepts such as the patent law concept of "analogous arts" that determines the prior art which is considered in assessing non-obviousness.

Another area in which a network approach shows promise is the evaluation of the extent to which increased patenting is related to the emergence of patent thickets and blocking patents. Network-based measures of local structure may be able to distinguish on average between patent thickets and areas of patenting of competing technologies. This approach may even be helpful in distinguishing between socially valuable patent pools and anti-competitive cross-licensing arrangements.

In this Article we have provided only a small sample of the application of network science to legal problems. Much remains to be done in applying network science to the patent system and to other legal issues. 


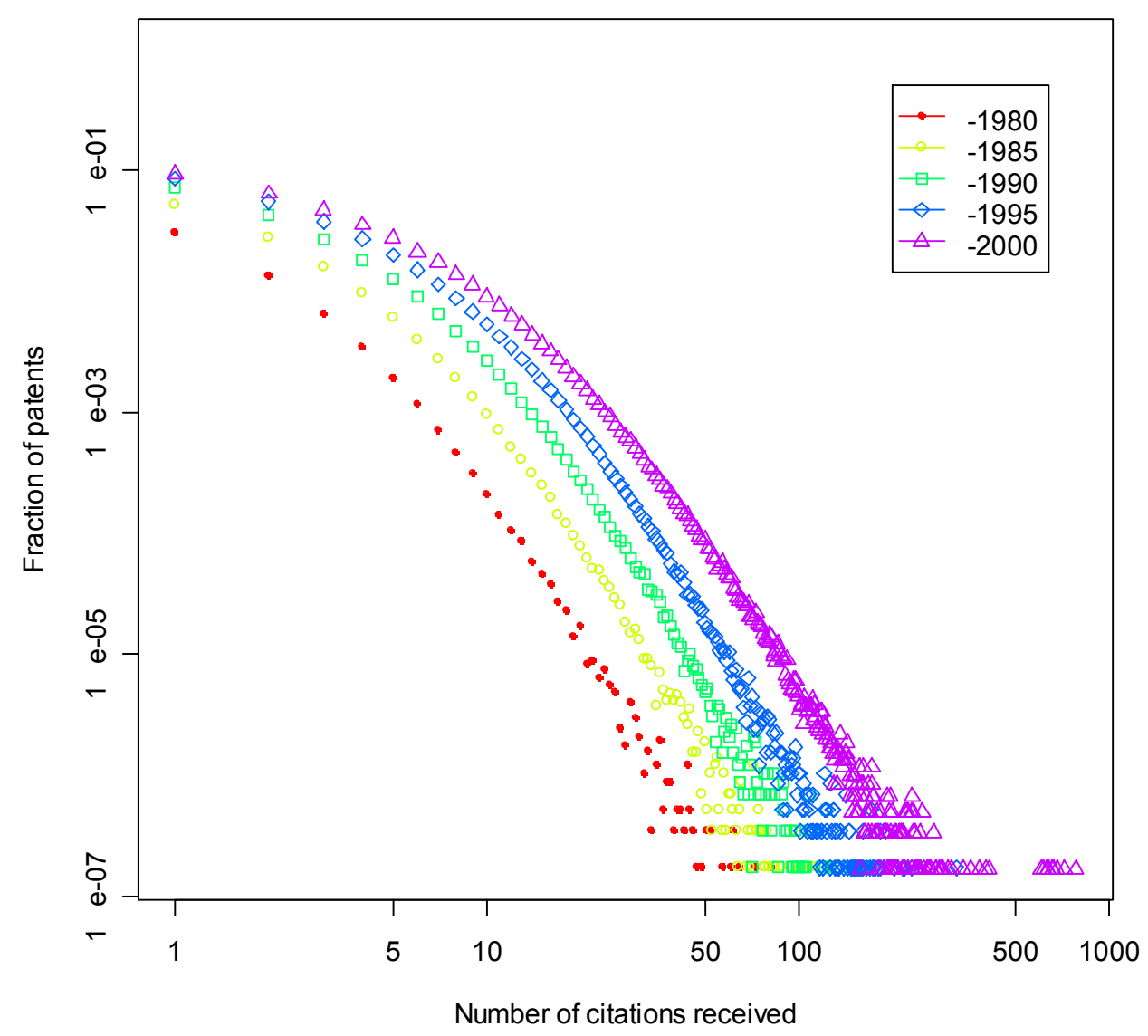

Figure 1: Distributions of number of citations received for the patent citation network at various times, shown on a log-log plot. A scale-free, power law distribution would be a straight line on this plot. Note that here the curvature increases as the network grows larger, inconsistent with the predictions of pure preferential attachment and consistent with the effects of patent aging. 


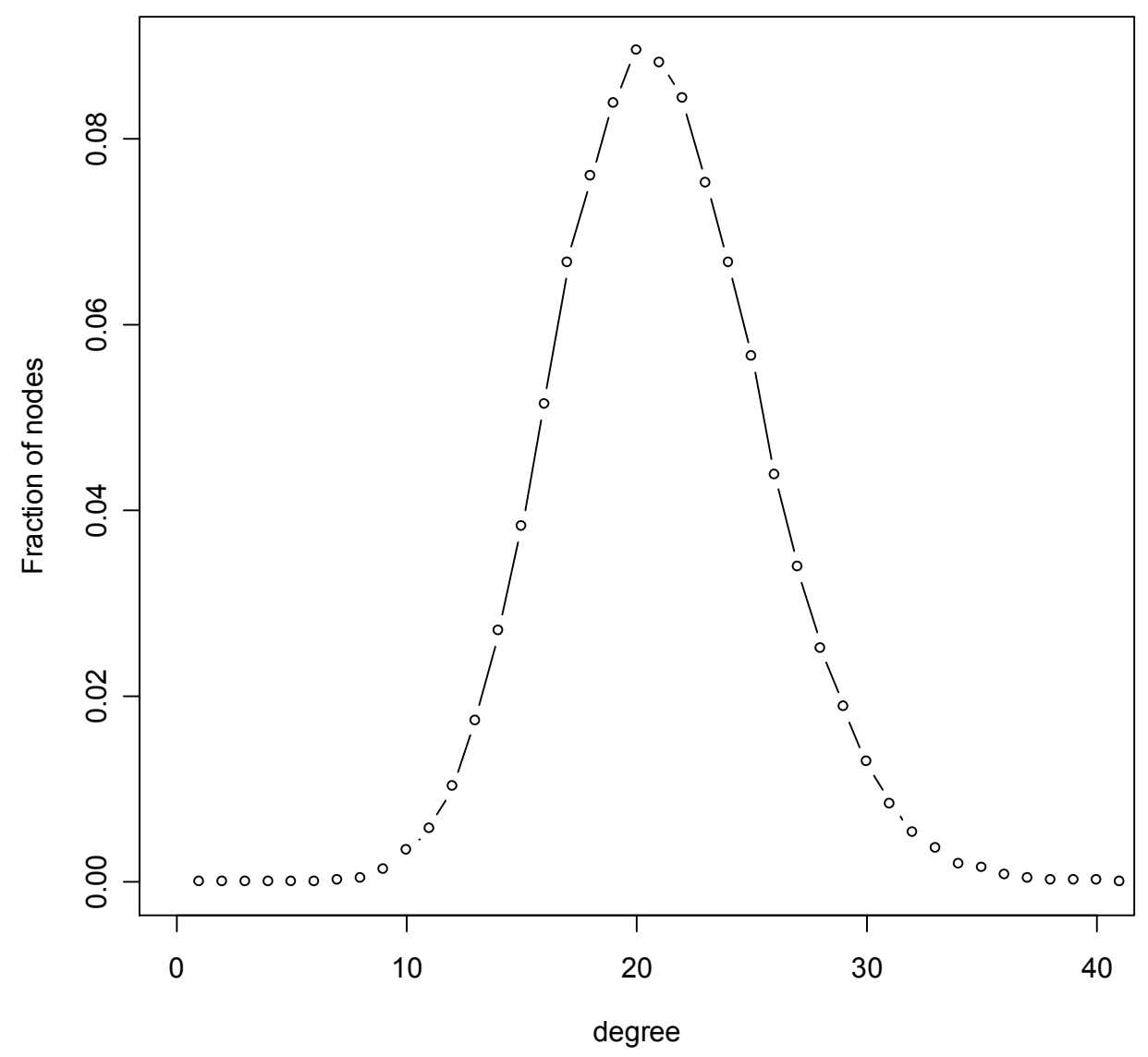

Figure 2: The degree distribution for a random network. The shape is a Poisson distribution. 


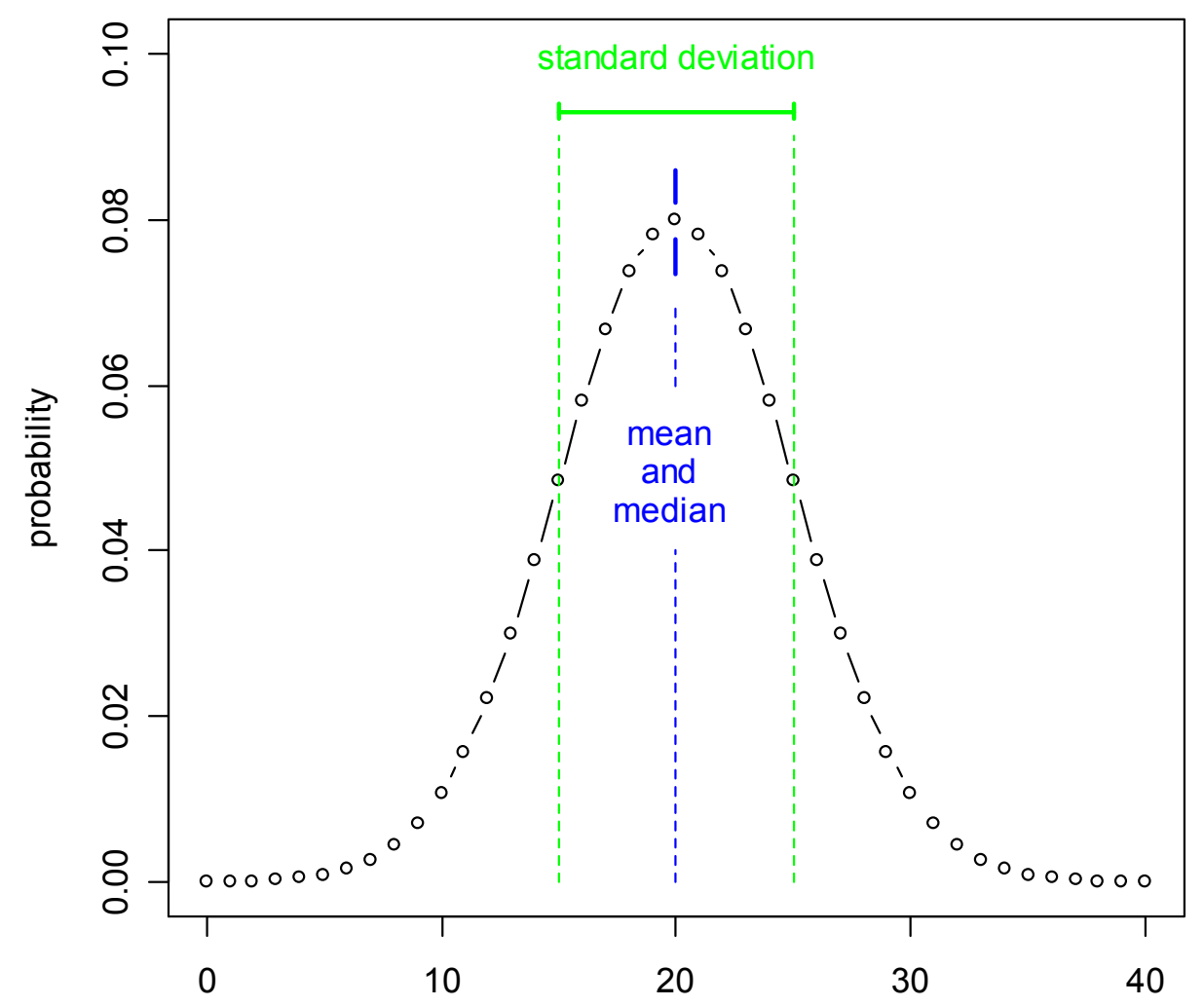

Figure 3: This figure illustrates the "normal" distribution or "Bell curve" that characterizes many probability distributions. It is symmetric, strongly peaked, and has a well-defined mean and median which are equal to one another. The probability outside of a few standard deviations from the mean is very small. 

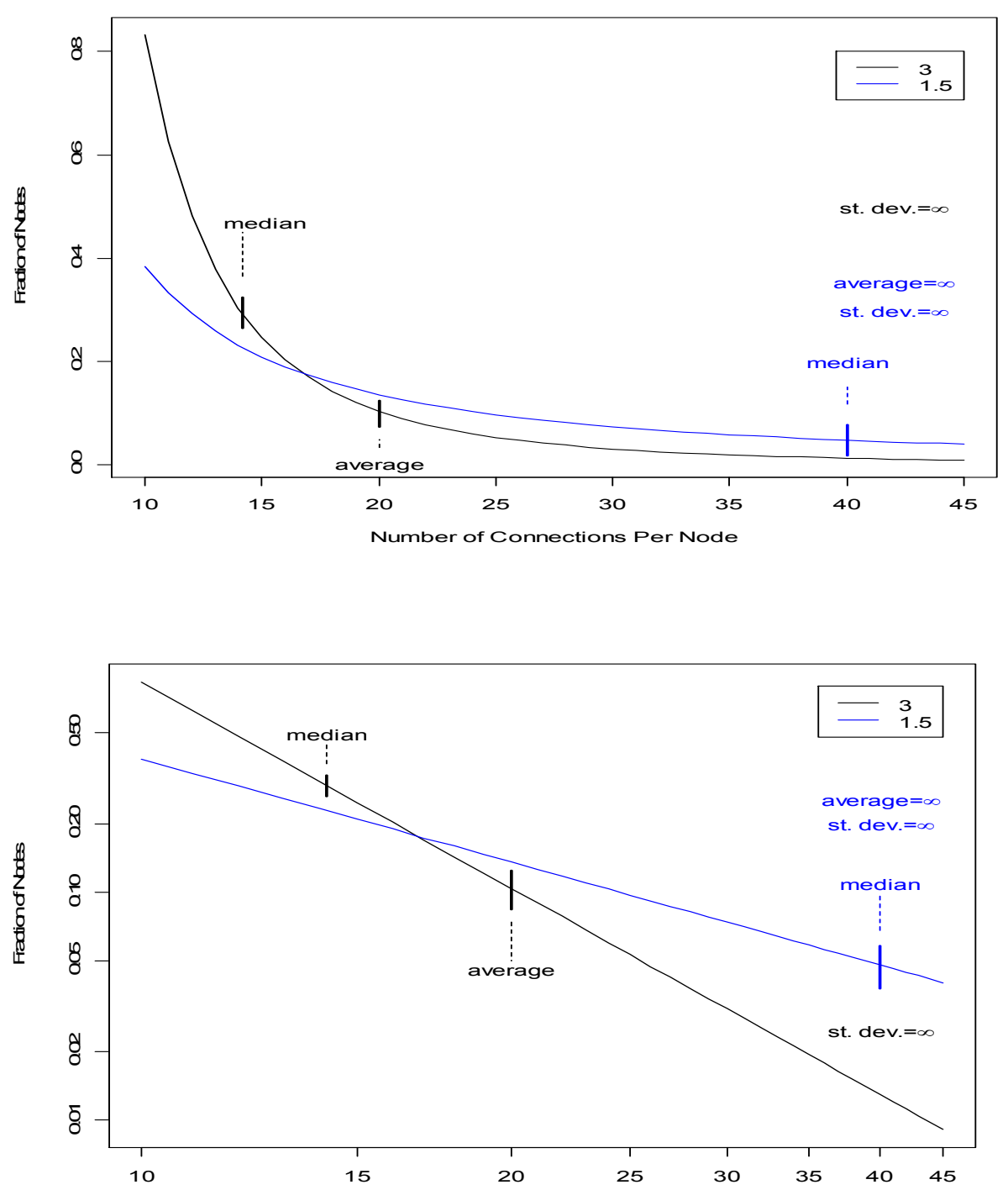

Figure 4: Top: This figure illustrates power law or "scale-free" probability distributions of node degree for two values of the decay exponent. Unlike the normal distribution, these distributions are highly skewed and cannot be meaningfully characterized by a "typical" value. Depending upon the decay exponent, the mean and median values can be quite far from one another. Indeed, if the decay exponent is small enough, the mean (or average) value is infinite even though the most likely value is zero. The standard deviation is infinite for both of the exponent values shown. Bottom: The same distributions are shown on a "log-log" plot, in which power law distributions are straight lines. 


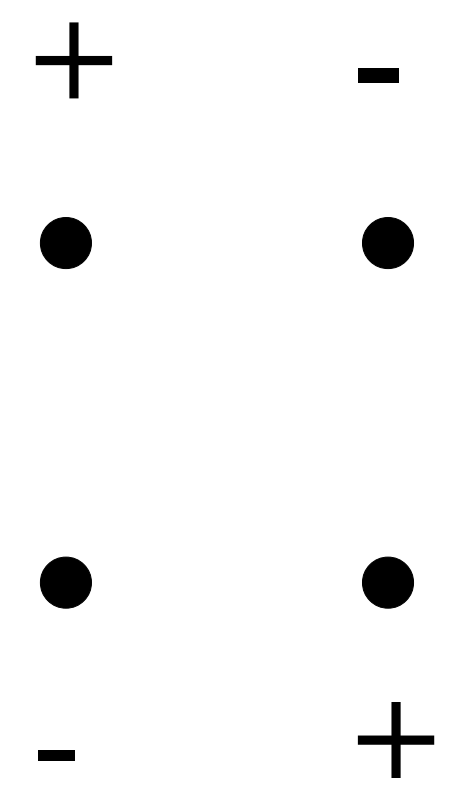

Anti-Ferromagnetic Ising Model on a Square Lattice -- All Neighbor Pairs Can Disagree

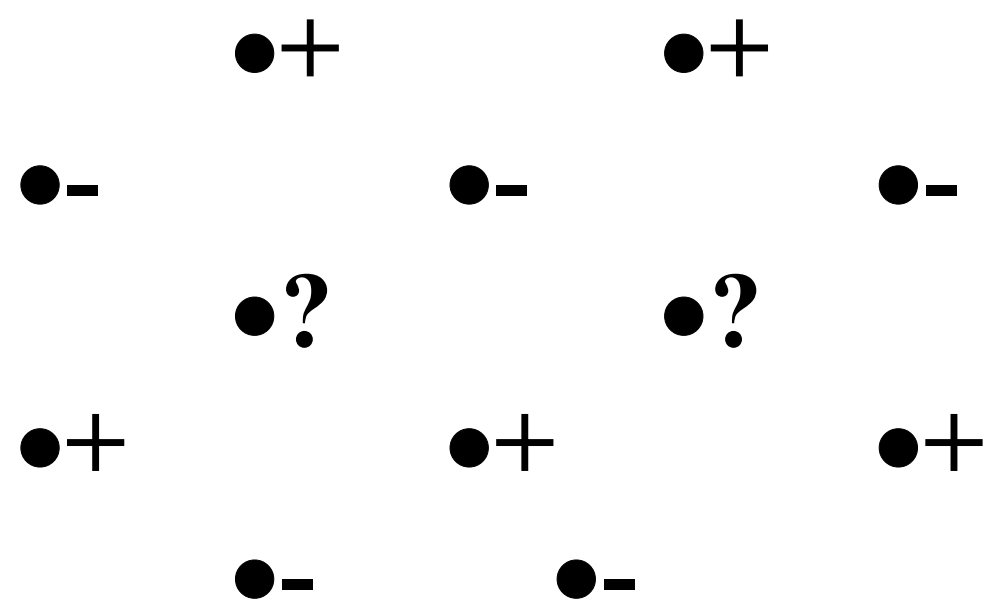

Anti-Ferromagnetic Ising Model on Triangular Lattice -- Some Neighbor Pairs Must Agree

Figure 5: Illustration of how local structure may affect optimal collective behavior even when the preferred relationships between local pairs are the same. 


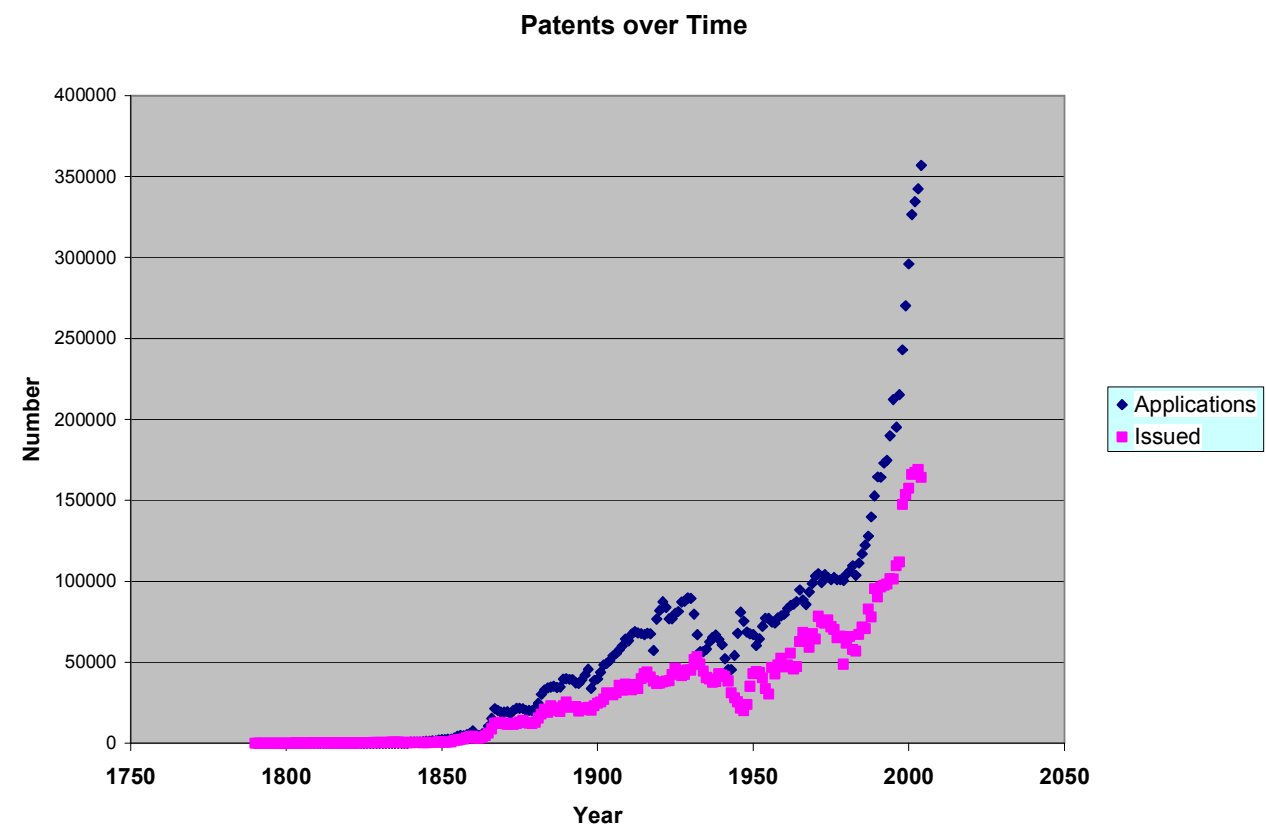

Log Patents over Time

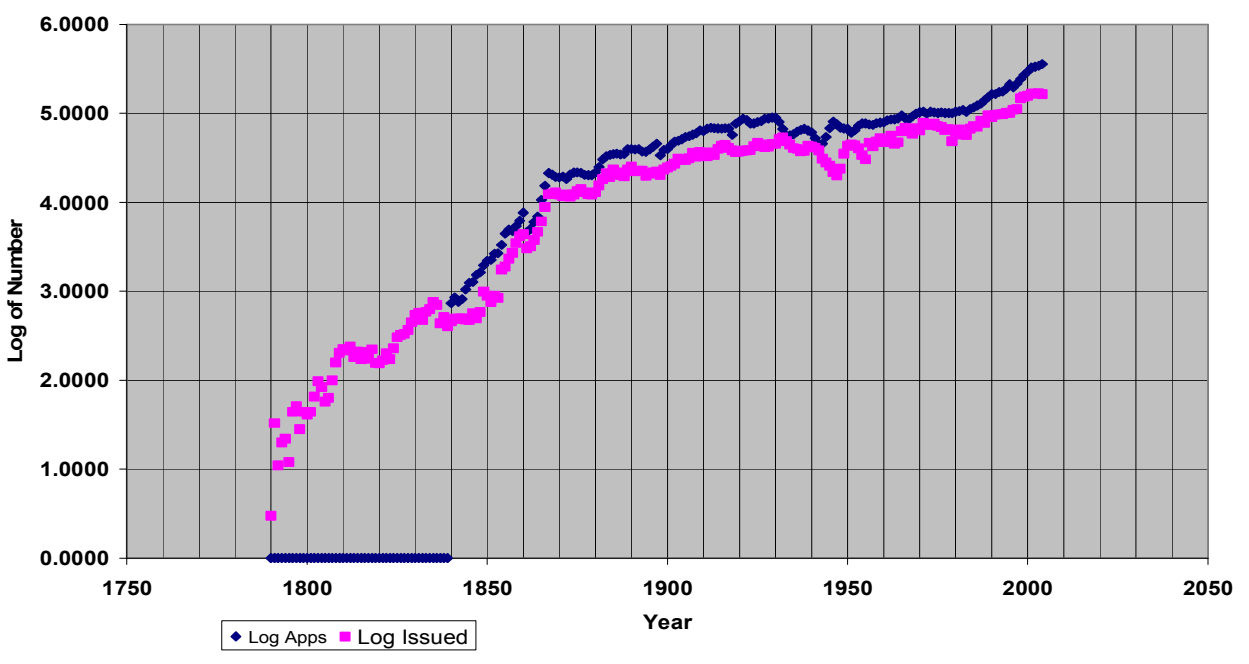

Figure 6: Top: Number of patents issued and applications filed per year as a function of time on a linear scale. Bottom: Number of patents issued and applications filed per year on a semi-log scale where linear portions correspond to exponential growth. (Note that patents were issued without examination from 1793-1836.) 

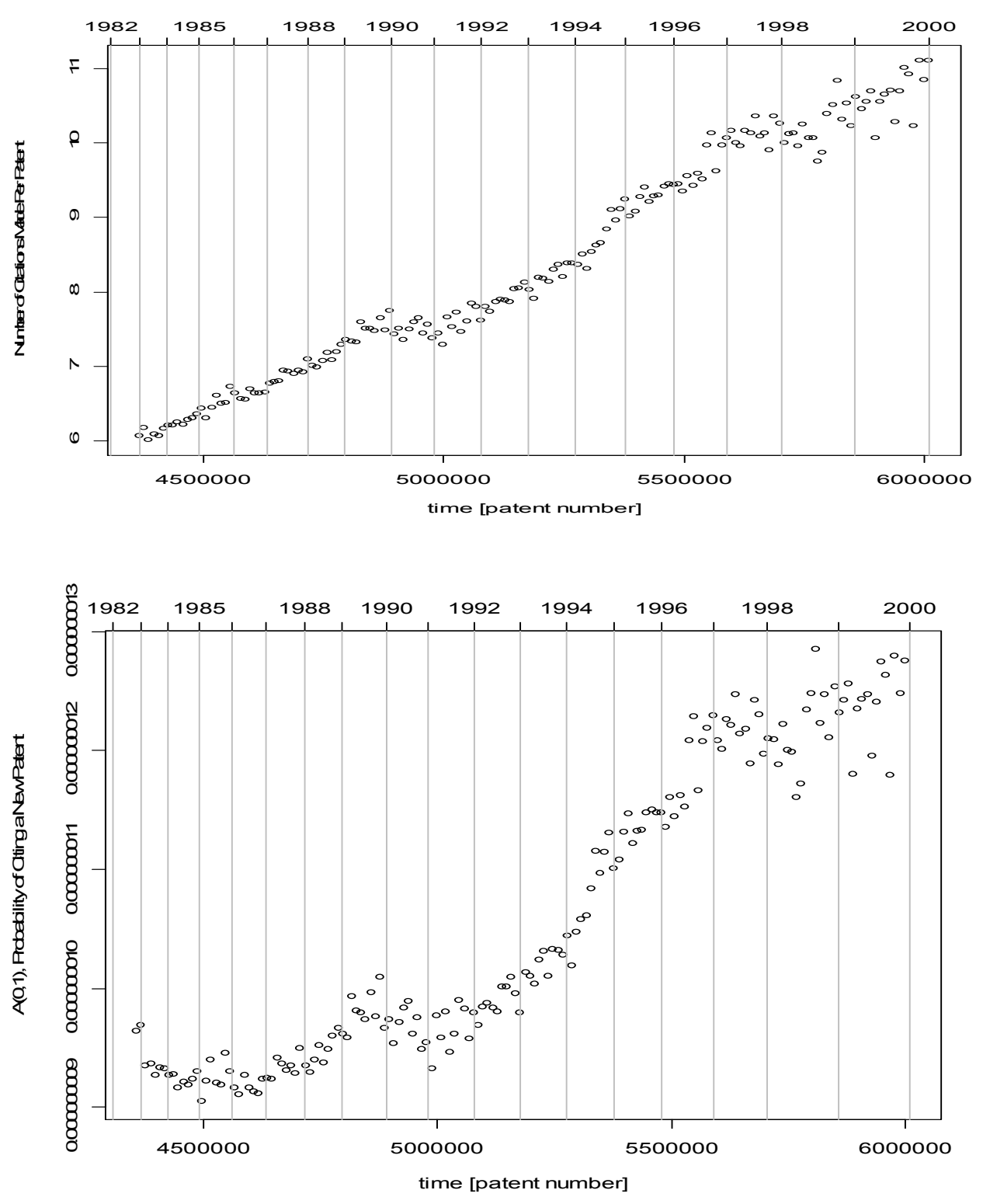

Figure 7: Top: Average number of citations made per patent as a function of time in patent number units. Bottom: Probability that a new patent will be cited as a function of time in patent number units. 


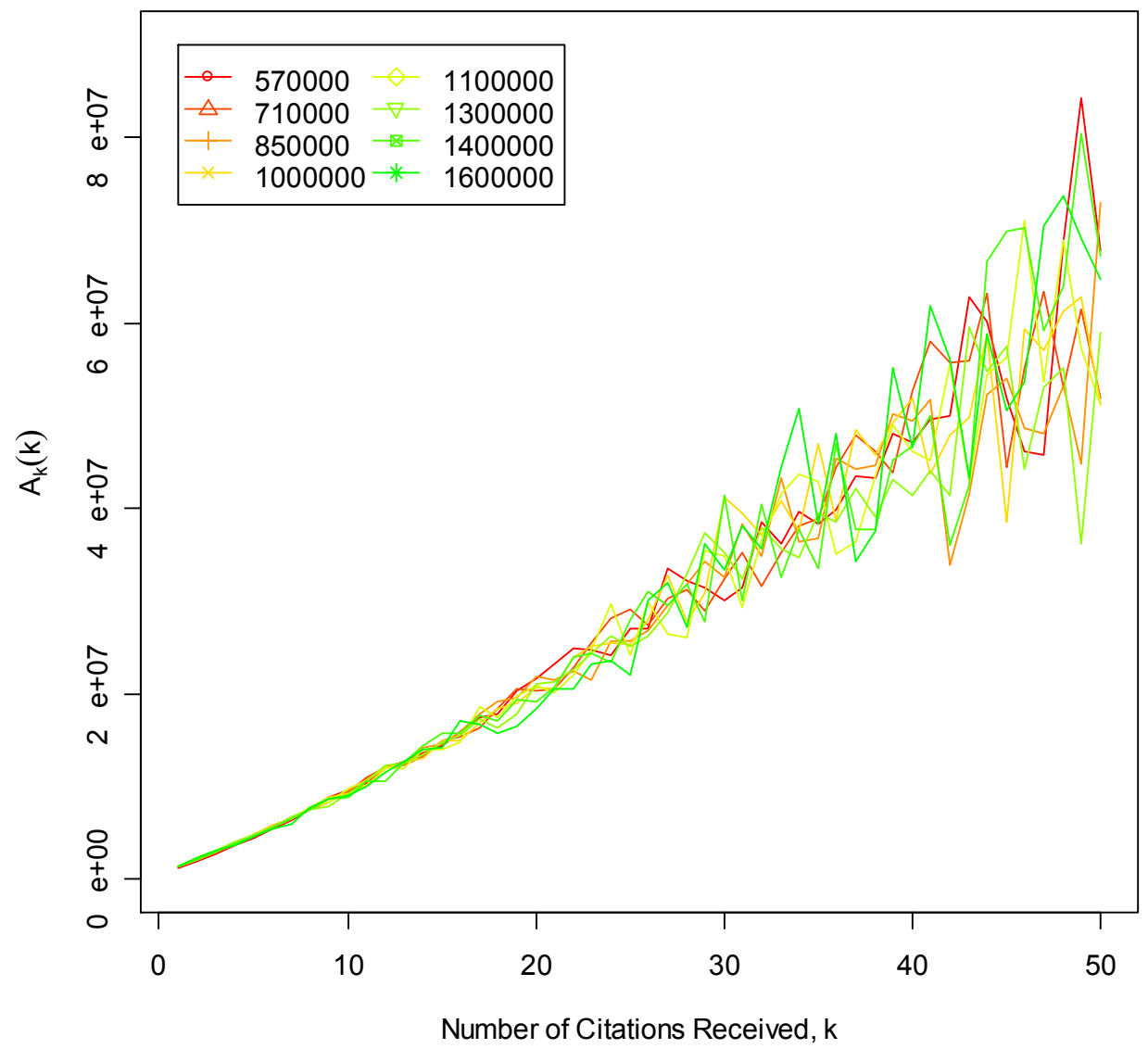

Figure 8: $A_{k}(k)$ as a function of number of citations received, $k$, for various values of patent age, 1 . 

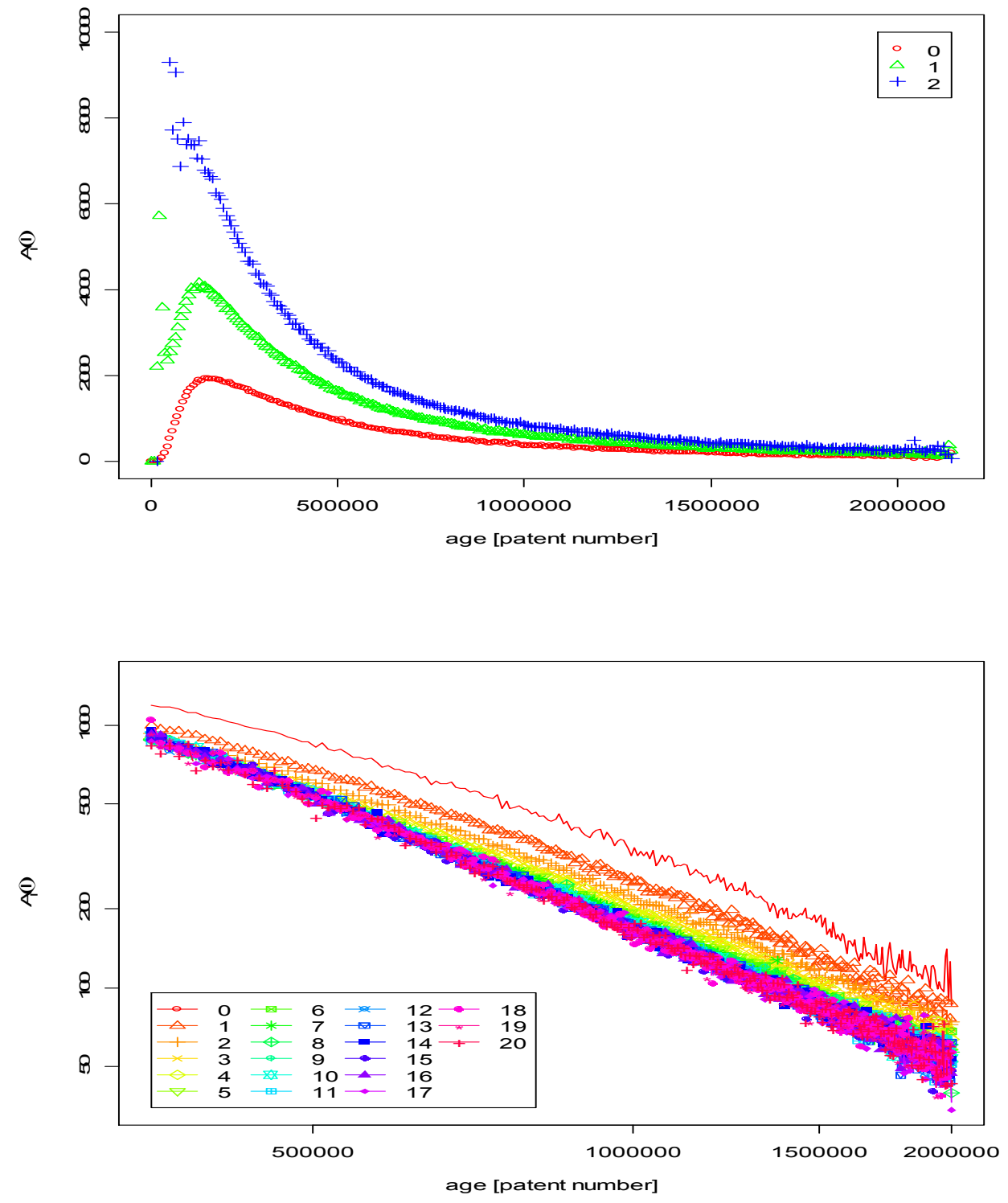

Figure 9: Top: $A(k, 1)$ as a function of patent age 1 , in units of patent number, for various values of in-degree, $\mathrm{k}$. Bottom: The decaying portion of $\mathrm{A}_{1}(1)$ as a function of patent age 1 , for various values of $k$. 


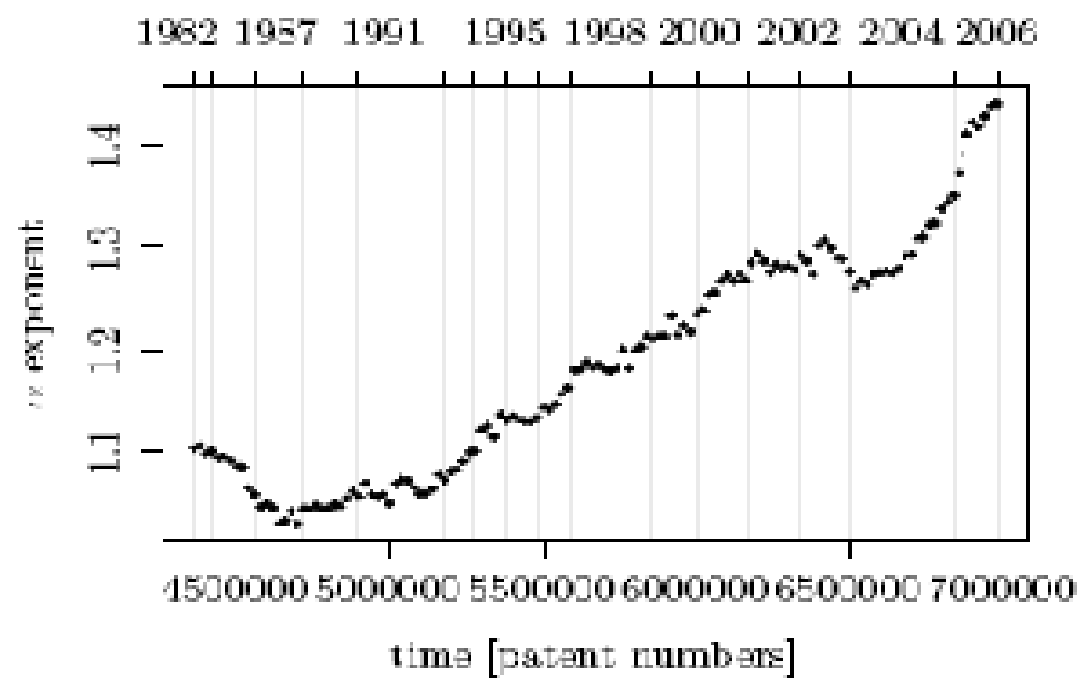

Figure 10: Stratification parameter, $\alpha$, as a function of time. 


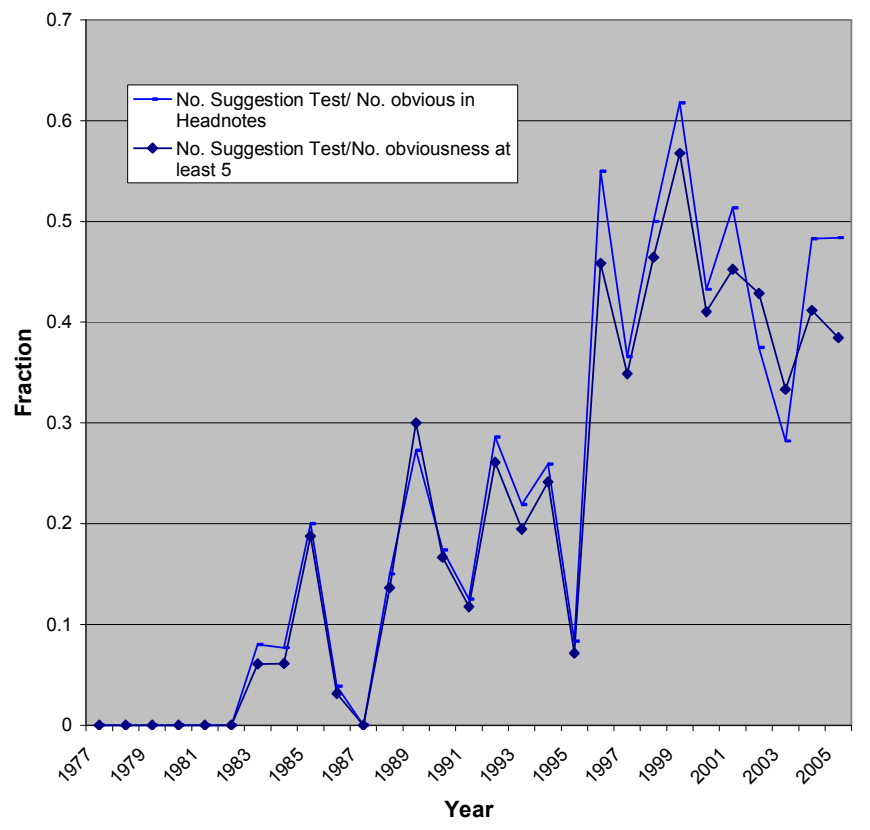

Figure 11: Fraction of Federal Circuit cases involving obviousness that referred to the "suggestion, teaching, or motivation to combine" test as a function of time. These numbers were obtained using LEXIS searches for "(suggestion or motivation or teaching) w/s combine" (to count references to the suggestion test) and either a reference to "obvious" in the headnotes (dashes) or at least 5 uses of the word "obvious" in the case (diamonds). These two methods of counting yield the same qualitative results showing an increase in use of the suggestion test throughout the 1990s. 


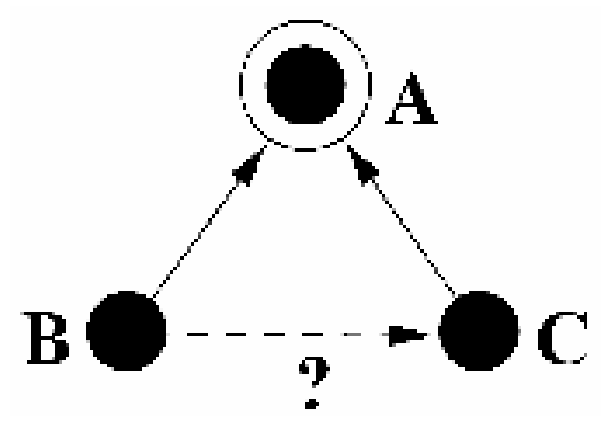

(a)

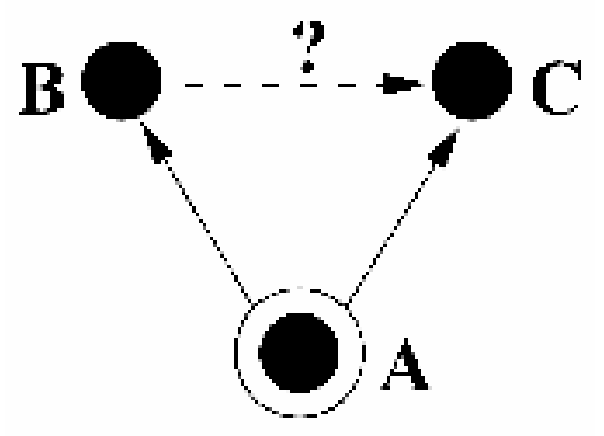

(b)

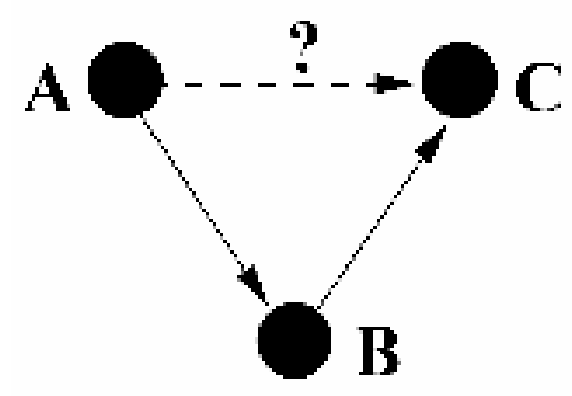

(c)

Figure 12: Illustrations of definitions of transitivity relevant to (a) generality; (b) originality; (c) whether citation from B to C likely indicates a "design around" or a blocking patent 
